\title{
Indo-Western Pacific Ocean Capacitor and Coherent Climate Anomalies in Post-ENSO Summer: A Review
}

\author{
Shang-Ping XIE*1,2, Yu KOSAKA ${ }^{3}$, Yan DU ${ }^{4}$, Kaiming HU ${ }^{5}$, Jasti S. CHOWDARY 6 , and Gang HUANG ${ }^{5}$ \\ ${ }^{1}$ Scripps Institution of Oceanography, University of California San Diego, La Jolla, California 92093-0206, USA \\ ${ }^{2}$ Physical Oceanography Laboratory/Qingdao Collaborative Innovation Center of Marine Science and Technology, \\ Ocean University of China, Qingdao, Shandong 266100 \\ ${ }^{3}$ Research Center for Advanced Science and Technology, University of Tokyo, Tokyo 153-8904, Japan \\ ${ }^{4}$ State Key Laboratory of Tropical Oceanography, South China Sea Institute of Oceanology, \\ Chinese Academy of Sciences, Guangzhou 510301 \\ ${ }^{5}$ State key Laboratory of Numerical Modeling for Atmospheric Sciences and Geophysical Fluid Dynamics and Center for \\ Monsoon System Research, Institute of Atmospheric Physics, Chinese Academy of Sciences, Beijing 100029 \\ ${ }^{6}$ Indian Institute of Tropical Meteorology, Pune 411 008, India
}

(Received 5 August 2015; revised 23 October 2015; accepted 5 November 2015)

\begin{abstract}
ENSO induces coherent climate anomalies over the Indo-western Pacific, but these anomalies outlast SST anomalies of the equatorial Pacific by a season, with major effects on the Asian summer monsoon. This review provides historical accounts of major milestones and synthesizes recent advances in the endeavor to understand summer variability over the Indo-Northwest Pacific region. Specifically, a large-scale anomalous anticyclone (AAC) is a recurrent pattern in post-El Niño summers, spanning the tropical Northwest Pacific and North Indian oceans. Regarding the ocean memory that anchors the summer AAC, competing hypotheses emphasize either SST cooling in the easterly trade wind regime of the Northwest Pacific or SST warming in the westerly monsoon regime of the North Indian Ocean. Our synthesis reveals a coupled oceanatmosphere mode that builds on both mechanisms in a two-stage evolution. In spring, when the northeast trades prevail, the AAC and Northwest Pacific cooling are coupled via wind-evaporation-SST feedback. The Northwest Pacific cooling persists to trigger a summer feedback that arises from the interaction of the AAC and North Indian Ocean warming, enabled by the westerly monsoon wind regime. This Indo-western Pacific ocean capacitor (IPOC) effect explains why El Niño stages its last act over the monsoonal Indo-Northwest Pacific and casts the Indian Ocean warming and AAC in leading roles. The IPOC displays interdecadal modulations by the ENSO variance cycle, significantly correlated with ENSO at the turn of the 20th century and after the 1970s, but not in between. Outstanding issues, including future climate projections, are also discussed.
\end{abstract}

Key words: Indian Ocean, western Pacific ocean-atmosphere interaction, ENSO, Asian monsoon

Citation: Xie, S.-P., Y. Kosaka, Y. Du, K. M. Hu, J. S. Chowdary, and G. Huang, 2016: Indo-western Pacific ocean capacitor and coherent climate anomalies in post-ENSO summer: A review. Adv. Atmos. Sci., 33(4), 411-432, doi: 10.1007/s00376015-5192-6.

\section{Introduction}

ENSO is the dominant mode of interannual variability. Arising from Pacific ocean-atmosphere interaction, ENSO affects climate around the globe through atmospheric teleconnections and by inducing SST responses in other ocean basins. The atmospheric response to SST anomalies in the tropical Pacific has been extensively studied, including the Pacific-North American (PNA) teleconnection pattern (Trenberth et al., 1998; Alexander et al., 2002). Not as well-known

\footnotetext{
* Corresponding author: Shang-Ping XIE

Email: sxie@ucsd.edu
}

but of regional importance are ENSO-correlated climate anomalies after ENSO has peaked. Here, we focus on the summer climate of the Indo-Northwest Pacific region, which encompasses South, Southeast and East Asia, home to more than three billion people. Summer is the rainy season for the Asian monsoon region, often accounting for more than $50 \%$ of the annual precipitation. The leading EOF mode of summer rainfall variability in the Indo-Northwest Pacific region (north of $10^{\circ} \mathrm{N}$ ) is significantly correlated with ENSO-not concurrently, but at a two-season lag. Such pronounced climate anomalies develop in post-ENSO summers when equatorial Pacific SST anomalies have largely dissipated. Our review tells the story of how these anomalies were identified, 
and their patterns and mechanisms unraveled.

In summer, the Indo-Northwest Pacific oceans are occupied by some of the warmest water of the global ocean. SST generally exceeds $28^{\circ} \mathrm{C}$ or even $29^{\circ} \mathrm{C}$, except in the western Arabian Sea and during intraseasonal upwelling events off South Vietnam in the South China Sea (SCS). Atmospheric convection is active over this Indo-Northwest Pacific warm pool, organized into several regional centers (off the west coast of India, in the Bay of Bengal and SCS; Fig. 1). The southwest monsoon winds prevail from the Arabian Sea through the SCS up to $140^{\circ} \mathrm{E}$, while the easterly trade winds prevail to the east. The division of the westerly monsoon and easterly trade wind regimes proves important for SST variability, as will become clear. Over East Asia, there is a northeastward-slanted rain band called Mei-yu in China, Changma in Korea, and Baiu in Japan. It brings the rainy season and is the single most important climate phenomenon to the region (Ding and Chan, 2005). ENSO is a major driver for climate variability over the Indo-Northwest Pacific region.

ENSO is phase-locked to the annual cycle. Typically, eastern Pacific (Niño3.4) SST anomalies begin to develop in June-August [JJA(0)], peak in December(0), and decay rapidly in April(1) (Fig. 2a). Here, the numerals in parentheses denote the ENSO developing (0) and decay (1) years. Seasons refer to those in the NH. Compared to the wellknown concurrent $[\mathrm{JJA}(0)]$ anomalies of the Indian summer monsoon that are anchored by tropical Pacific SST anomalies, JJA(1) anomalies in the atmosphere may seem peculiar without robust Niño3.4 SST anomalies, but are well documented. Over the tropical Northwest (TNW) Pacific, rainfall variability is better correlated with ENSO in JJA(1) than $\mathrm{JJA}(0)$ (Fig. 2b), and there are fewer tropical cyclones (TCs) in post-El Niño summers (Du et al., 2011). These JJA(1) atmospheric anomalies are consistent with the result of Harrison and Larkin (1996) that ENSO-induced anomalies of SLP last through September(1) over the TNW Pacific, the longest persistence in their surface meteorological analysis. The long-lasting SLP anomalies turn out to be part of a large-scale anomalous anticyclone over the TNW Pacific, which develops at the peak of El Niño and persists through JJA(1) (Wang et al., 2003). The summer anomalous anticyclone (AAC) is associated with suppressed local convection and part of the Pacific-Japan (PJ) pattern Nitta (1986) identified originally from analysis of reflective cloud cover.

The identification of the AAC development following El Niño is a major advance in Asian monsoon research. The AAC affects the East Asian summer monsoon to the north (Huang and Wu, 1989; Chang et al., 2000) via the PJ pattern and the Indian summer monsoon to the west (Mishra et al., 2012). In post-ENSO summers without robust SST anomalies in the equatorial Pacific, the recurrent AAC must be anchored by ocean memory elsewhere. Identifying this ocean memory proved not straightforward and took many turns. The initial search naturally focused on the TNW Pacific, but with mixed results (Nitta, 1987). Wang et al. (2000) proposed a wind-evaporation-SST (WES) feedback mechanism acting on the prevailing winter northeasterly monsoon winds. The challenge is how to apply this winter mechanism to summer when the northeast trade wind regime retreats east of $140^{\circ} \mathrm{E}$ (Fig. 1).

In JJA(1), the most robust El Niño-induced SST anomalies of the global ocean are found in the tropical Indian Ocean (IO) and SCS. It is well known that the tropical IO warms up a season after El Niño (Weare, 1979) but the IO warming has previously been viewed as a passive response to El Niño without a climatic effect. This idea is supported by the observations that in the developing and mature stages of El Niño, atmospheric convection is suppressed, instead of being energized, over the warming tropical IO. The second difficulty in invoking SST anomalies in the IO-TNW Pacific warm pool as the ocean memory for JJA(1) atmospheric anomalies is the fact that the local SST-precipitation relationship is weak in the region (Wang et al., 2005; Wu and Kirtman, 2007). This difficulty notwithstanding, observational analysis reveals a Matsuno (1966)-Gill (1980) pattern in the free troposphere that is consistent with the forcing by a warming IO and can

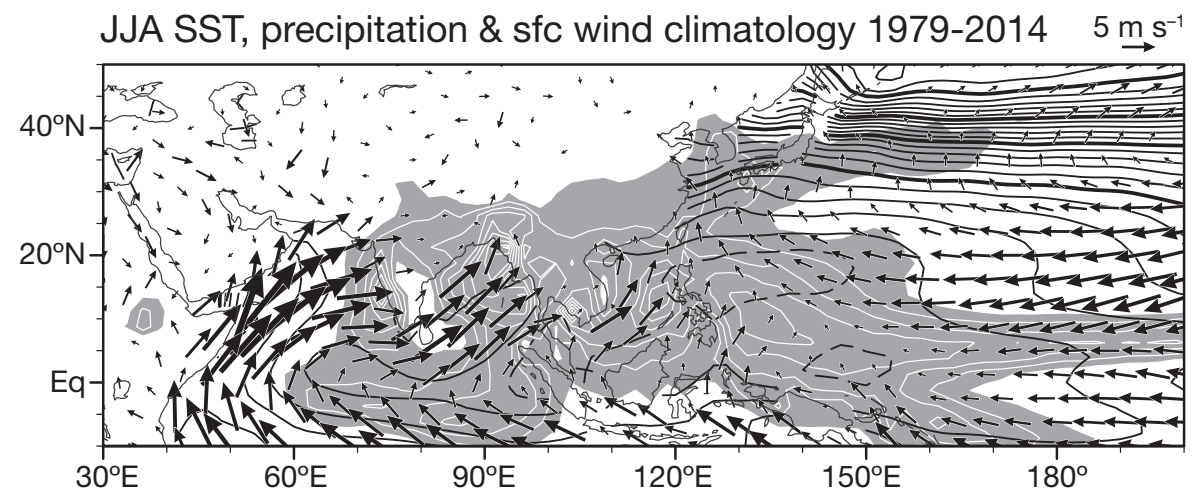

Fig. 1. Summer (JJA) climatology over the Indo-western Pacific for 1979-2014: SST (black contours; interval $=1{ }^{\circ} \mathrm{C}$; thick contours for $10^{\circ} \mathrm{C}, 15^{\circ} \mathrm{C}, 20^{\circ} \mathrm{C}$ and $25^{\circ} \mathrm{C}$ and dashed contours for $29.5^{\circ} \mathrm{C}$ ), precipitation (gray shading representing $>5 \mathrm{~mm} \mathrm{~d}^{-1}$, and white contours for $7,9,11, \ldots \mathrm{mm} \mathrm{d}^{-1}$ ), and surface wind velocity (arrows, $\mathrm{m} \mathrm{s}^{-1}$ ) [based on ERSST.v3b (Smith et al. 2008), CMAP (Xie and Arkin, 1997) and JRA-55 (Kobayashi et al., 2015)]. 
give rise to an AAC over the TNW Pacific (Xie et al., 2009). Modeling studies support this IO forcing of the TNW Pacific AAC (Wu and Liu, 1995; Li et al., 2008; Huang et al., 2010; Wu et al., 2010; Chowdary et al., 2011).

The perception that the tropical IO is largely passive also stems from the observational result that the North IO response to ENSO can be largely explained from surface heat flux adjustments (via the cloud radiative effect and windinduced latent heat flux) without invoking ocean dynamics. Challenging this passive IO view is the recent observational result that the SST response to El Niño features two peaks over the North IO (Du et al., 2009) and SCS (Wang et al., 2006); the first peak coincides with the peak phase of El Niño but the second one is in the post-El Niño summer (Fig. 2a). The summer peak is peculiar as it cannot be forced directly by El Niño. Instead, it results from positive feedback of the Indo-TNW Pacific ocean-atmosphere interaction that prolongs the response to El Niño (Du et al., 2009; Kosaka et al., 2013; Wang et al., 2013). In a post-El Niño summer, JJA(1), the North IO is kept warm by the anomalous easterlies on the south flank of the TNW Pacific AAC, which oppose the prevailing southwest monsoon and reduce surface evaporation (Du et al., 2009). Meanwhile, the North IO warming anchors the AAC via an atmospheric Kelvin wave adjustment (Xie et al., 2009). This new coupled mode of Indo-TNW Pacific cross-basin interaction explains why ENSO anomalies last longest over the Indo-TNW Pacific and the AAC is the preferred pattern (Kosaka et al., 2013). This is analogous to the Indian Ocean dipole (IOD) mode (Saji et al., 1999), which is excited by El Niño but takes up a distinctive pattern characteristic of Bjerknes feedback.

Major advances have been made in describing and explaining post-ENSO ocean-atmospheric anomalies over the Indo-TNW Pacific warm pool. A new paradigm is emerging that depicts an IO that is more dynamically and climatically active than previously thought. It reveals a new kind of interbasin interaction between the tropical IO and TNW Pacific mediated by the AAC. Elements of the paradigm have been published over more than a decade, and here we synthesize these advances with outlooks for further progress.

This review aims to summarize recent progress in studying how ENSO forces the Indo-TNW Pacific oceans and how this response develops and persists to exert climatic influences. The rest of the paper is organized as follows: Section 2 introduces post-ENSO anomalies in the ocean and atmosphere. It addresses questions of what are the major anomalies and how they are related to each other. Historical perspectives are provided of how progress has been made. Section 3 presents the coupled view and discusses the evidence. Section 4 explores the extent to which IO-TNW Pacific climate is predictable and highlights the challenges facing extratropical East Asian countries in developing skillful seasonal forecasts. Section 5 examines interdecadal variations in postENSO summer anomalies, based on historical observations that go back to the late 19th century. Section 6 is a summary with a conceptual model. It also discusses challenges in simulating Indo-Northwest Pacific climate and projecting
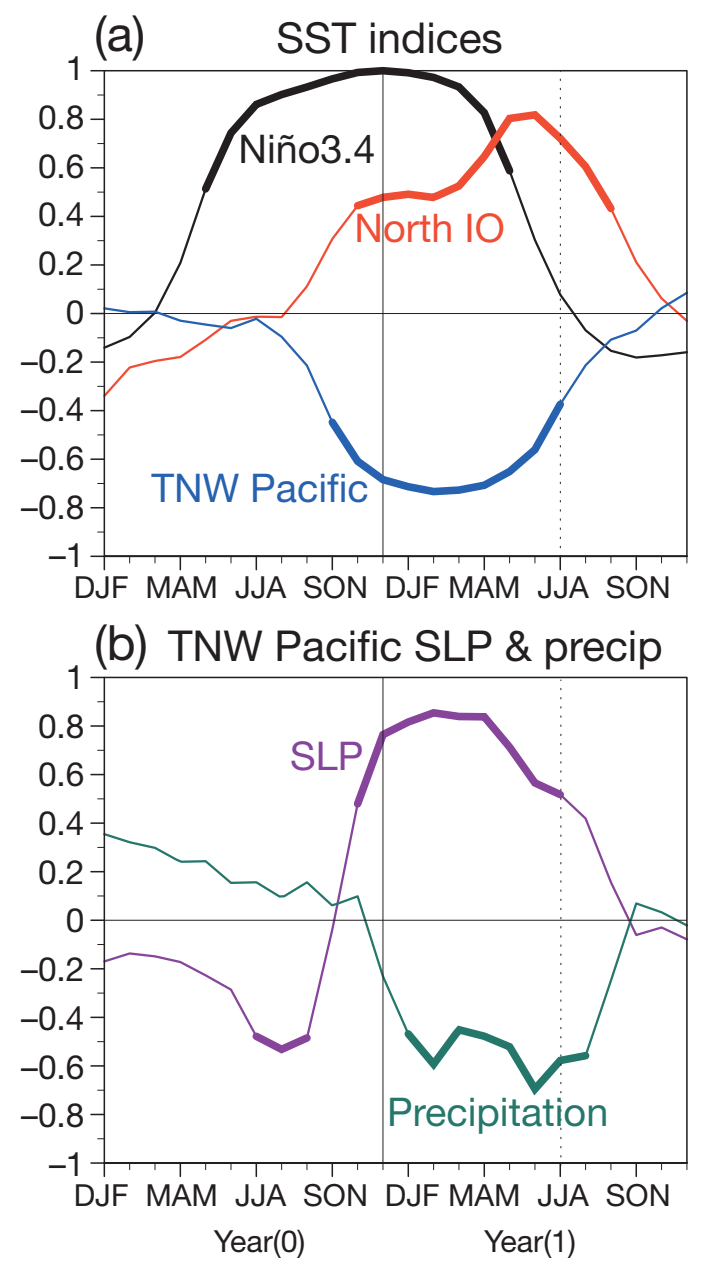

Fig. 2. Lagged correlations with $\mathrm{ND}(0) \mathrm{J}(1) \mathrm{Niño3.4} \mathrm{SST:} \mathrm{(a)}$ SST in the Niño3.4 region (black), North IO $\left(5^{\circ}-25^{\circ} \mathrm{N}, 40^{\circ}-\right.$ $100^{\circ} \mathrm{E}$; red), and TNW Pacific under the easterly trade wind regime $\left(10^{\circ}-20^{\circ} \mathrm{N}, 150^{\circ}-170^{\circ} \mathrm{E}\right.$; blue); (b) SLP (purple) and precipitation (green) over the TNW Pacific around Guam $\left(10^{\circ}-\right.$ $20^{\circ} \mathrm{N}, 135^{\circ}-155^{\circ} \mathrm{E}$ ) [thick curves indicate the $>95 \%$ confidence level, based on the $t$-test; three-month running averaging has been applied; based on ERSST, Hadley Centre sea level pressure, version 2 (Allan and Ansell, 2006) and CMAP for 1979-2014 (detrended)].

its change in the face of increasing greenhouse gas forcing.

\section{Ocean-atmosphere anomalies in post-ENSO summer}

This section highlights major anomalies over the summer tropical IO-TNW Pacific, with an historical account of how research has developed in the area, and a discussion of attendant anomalies in the extratropical East Asia.

\subsection{Long persistence of IO response to ENSO}

Using EOF analysis, Weare (1979) showed that positive IO SST anomalies are often associated with a warmer eastern tropical Pacific, even though observations were quite sparse 
in those early days (Kent et al., 2007). Accompanying the SST mode are coherent anomalies of rainfall and SLP over the Arabian Sea (Weare, 1979). The maximum warming of the IO occurs from March to May, lagging the peak of SST anomalies over the eastern Pacific by about 3 months (Nigam and Shen, 1993). Traditionally, the IO warming is considered basin-wide (Liu and Alexander, 2007; Schott et al., 2009) and due to surface heat flux changes induced by El Niño via an atmospheric bridge (Klein et al., 1999; Alexander et al., 2002). Recent studies have revealed that the IO warming is mechanistically distinct among sub-basins.

The early study of Klein et al. (1999) pointed out that sur- face flux anomalies cannot explain the warming in the Southwest IO. Atmospheric models coupled to a motionless mixed layer ocean, forced by observed SST over the tropical Pacific, underestimate the Southwest IO warming (Alexander et al., 2002; Lau and Nath, 2003). There is growing consensus that Southwest IO SST variability is caused by thermocline displacements forced by ENSO through an atmospheric bridge (Xie et al., 2002; Du et al., 2009). During the developing (September-November) and mature (DecemberFebruary) phases of El Niño, an anomalous anticyclone forms in the Southeast IO (Fig. 3a; Wang et al., 2000), associated with a weakened Walker circulation. In the South IO, the

(a) $\operatorname{DJF}(0 / 1)$
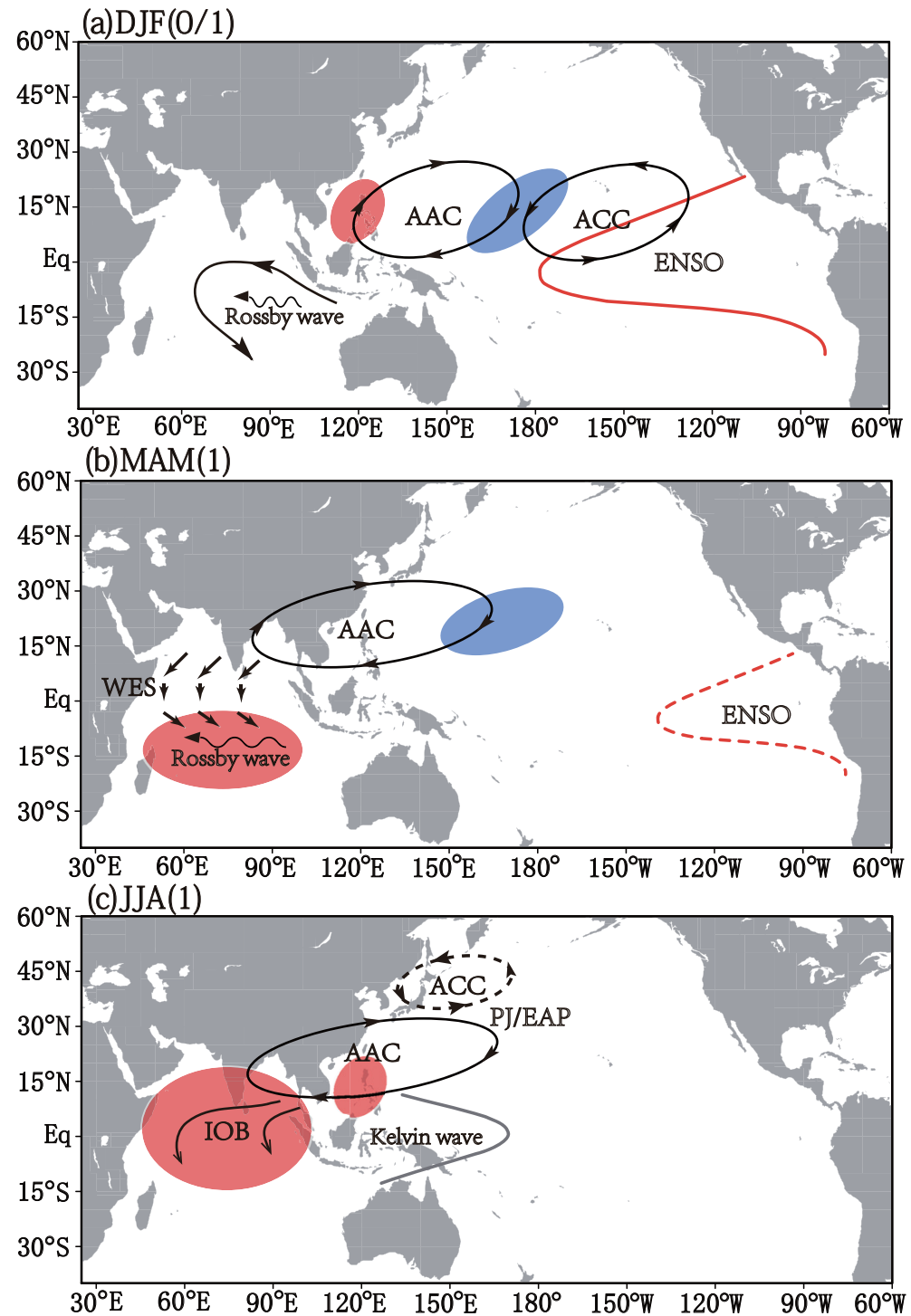

Fig. 3. Schematic representation of the major SST anomalies and atmospheric teleconnection over the Indo-Pacific oceans associated with El Niño events: (a) El Niño impacts on the South IO through westward Rossby waves during December-February; (b) Rossby waves inducing Southwest IO warming, which in turn induces an anti-symmetrical wind pattern over the tropical IO during March-May; (c) the second IO warming exciting a tropospheric Kelvin wave propagating into the western Pacific, forcing the AAC and PJ/EAP pattern to affect East Asia during the following summer. 
AAC forces downwelling ocean Rossby waves that propagate westward (Fig. 3b; Perigaud and Delecluse, 1993; Masumoto and Meyers, 1998; Ueda and Matsumoto, 2000). The Southwest IO is unique where the meridional shear of the trade winds maintains a thermocline ridge where thermocline feedback on SST is strong (Xie et al., 2002). The El Niño-induced downwelling Rossby waves deepen the thermocline, causing the Southwest IO to warm (Fig. 3b). The slow-propagating ocean Rossby waves anchor the Southwest IO warming, allowing it to persist through the following summer.

The Southwest IO warming anchors an asymmetrical pattern of anomalous atmospheric circulation over the tropical IO in the spring following El Niño, with the northeasterlies north and northwesterlies south of the equator (Figs. 3c and 4). The anti-symmetrical atmospheric pattern can be explained by the WES feedback of Xie and Philander (1994). During winter and the following spring, the Southwest IO warming induces wind anomalies across the equator, and the wind anomalies turn northeasterly over the North IO due to the Coriolis effect. The anomalous northeasterlies over the North IO intensify the climatological northeast winter monsoon and cool the sea surface (Kawamura et al., 2001; Wu et al., 2008). The anti-symmetrical pattern is also obvious in precipitation. The rainfall increases over the anomalously warm South IO with enhanced convection and decreases over the relatively cool North IO. With the wind reversal to the southwest monsoon in May, the anomalous northeasterly winds change to have a warming effect on the North IO by reducing latent heat flux (Du et al., 2009; Fig. 4). Although wind-induced latent heat flux is the mechanism, the second warming of the North Indian Ocean in the early summer following El Niño results from ocean-atmosphere interaction within the tropical IO as the anti-symmetric wind pattern is anchored by the slow-propagating downwelling Rossby waves south of the equator. This deviates from the previous paradigm that the tropical IO is climatically dormant and can be modeled as a motionless mixed layer. Section 3 shows that the ocean-atmosphere interaction for the second warming of the North IO and SCS extends beyond the IO and involves the TNW Pacific.

The largest SST anomalies in post-El Niño summer take place over the SCS because of ocean dynamic effects such as upwelling and gyre adjustments (Wang et al., 2002; Xie et al., 2003; Wang et al., 2006). The slow ocean dynamic adjustments also make SCS SST anomalies last longest of the global ocean (Yang et al., 2015). The shortwave cloud radiative effect also contributes to SCS SST variability (Klein et al., 1999; Wu et al., 2014).

\subsection{The PJ pattern}

The success of the thermally forced atmospheric Rossby wave theory of Hoskins and Karoly (1981) in explaining the observed excitation of the PNA pattern in winter by ENSO (Horel and Wallace, 1981) triggered a boom of research on tropical-extratropical teleconnections. From a teleconnectivity map based on six summers of monthly satellite cloud data, Nitta (1986) discovered a meridional dipole pattern of

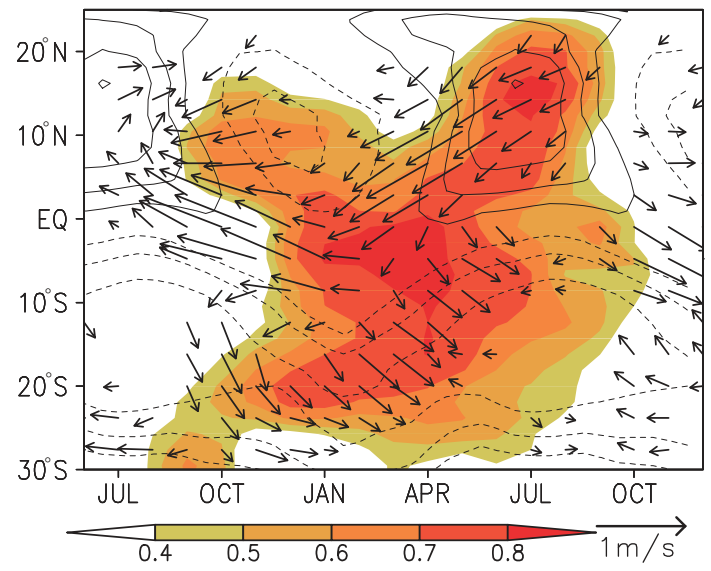

Fig. 4. Time-latitude section of regression upon $\mathrm{ND}(0) \mathrm{J}(1)$ Niñ3.4 SST: SST (shaded; ${ }^{\circ} \mathrm{C}$ ) and surface wind velocity (vectors), zonally averaged in the tropical IO $\left(40^{\circ}-100^{\circ} \mathrm{E}\right)$ [zonal wind climatology plotted in black contours $\left(2 \mathrm{~m} \mathrm{~s}^{-1}\right.$ intervals with zero omitted)]. Reprinted from Du et al. (2009).

cloudiness between the tropical $\left(15^{\circ}-25^{\circ} \mathrm{N}\right)$ and midlatitude $\left(30^{\circ}-40^{\circ} \mathrm{N}\right)$ Northwest Pacific: weaker-than-normal convective activity over the South China and Philippine seas is associated with an increase in Mei-yu frontal rainfall (Fig. 5b). Nitta (1987) named this teleconnection the PJ pattern [also known as the East Asia-Pacific (EAP) pattern, as per Huang and Sun (1992)]. Figure 5 shows the PJ pattern extracted as the leading EOF of $850 \mathrm{hPa}$ zonal wind over the summer Northwest Pacific multiplied by the Coriolis parameter, equivalent to the meridional pressure gradient. It is highly correlated with the principal components of the leading EOF modes of precipitation and lower-tropospheric vorticity in the region. Anomalous circulation in the lower troposphere exhibits a tripolar pattern (Fig. 5a). The PJ pattern refers to the dipole between the tropical and midlatitude lobes (association of the tropical and high-latitude lobes is weak). The PJ pattern dominates on intraseasonal to interannual time scales and affects summer temperature, precipitation, and TC landfall in East and Southeast Asia.

\subsubsection{Atmospheric dynamics}

Analogous to the winter PNA pattern, Nitta (1987), Kurihara and Tsuyuki (1987) and Huang and Sun (1992) suggested that the PJ pattern is a Rossby wave train excited by anomalous convection over the TNW Pacific. Nitta (1987) further speculated that the convection anomalies are forced by local SST anomalies. The PJ pattern has withstood the test of time but the excitation mechanism turns out to differ from what these early studies suggested.

An alternative view to linear Rossby waves riding on the zonal mean flow regards dominant teleconnection patterns such as the PNA as barotropically unstable modes that gain energy from the zonally varying background flow (Simmons et al., 1983). From this viewpoint, the PNA pattern is an internal dynamical mode of the atmosphere while external forcing such as ENSO modulates its probability. Along this line, Tsuyuki and Kurihara (1989) suggested that over the mid- 
(a) Sea level pressure

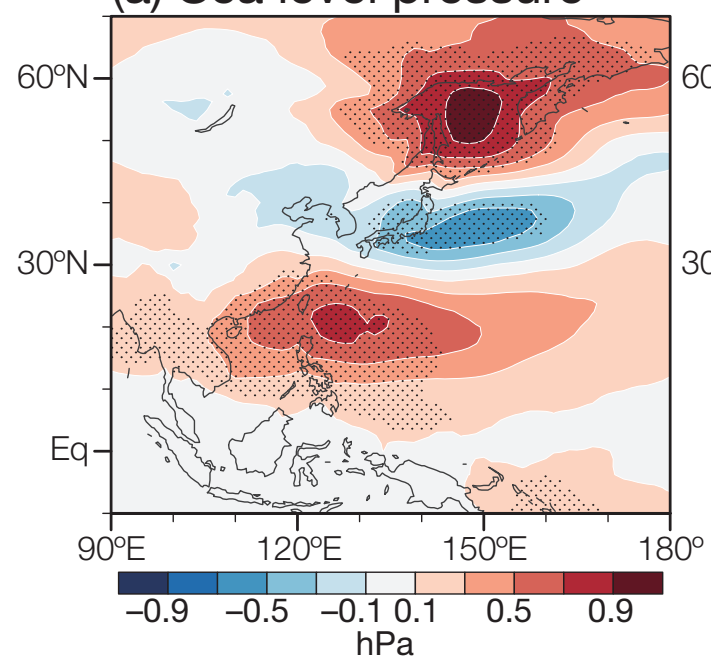

(c) $2 \mathrm{~m}$ air temperature

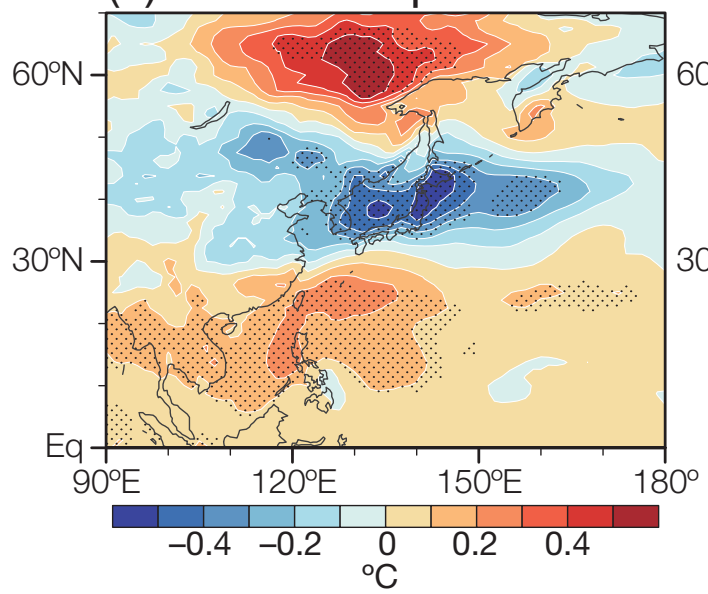

(b) Precipitation

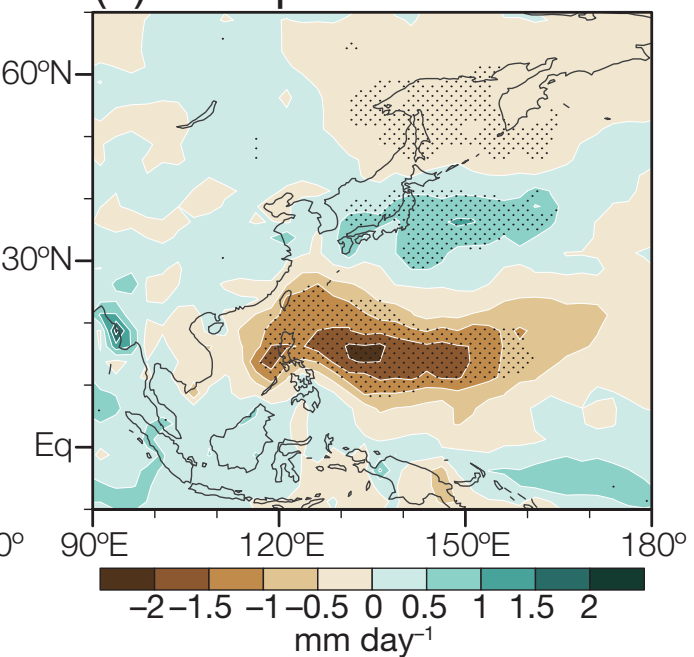

(d) TC occurrence

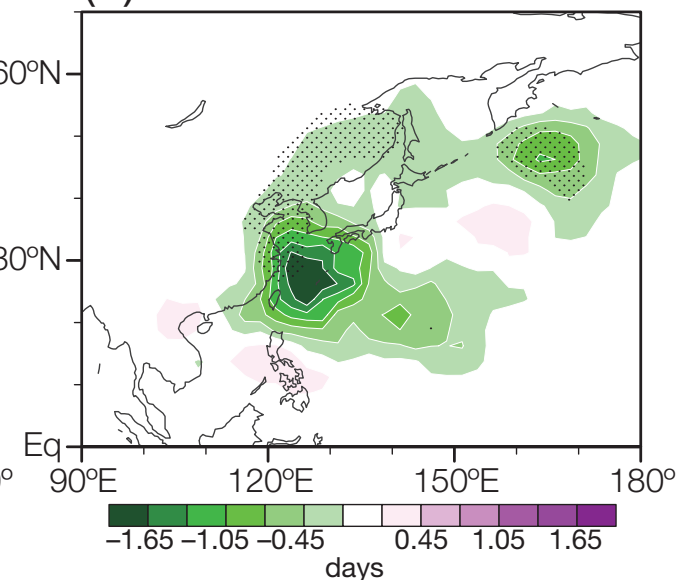

Fig. 5. Structure of the PJ pattern. Anomalies of (a) SLP, (b) precipitation, (c) $2 \mathrm{~m}$ air temperature, and (d) TC occurrence regressed against the leading principal component of JJA seasonal-mean zonal wind velocity at 850 $\mathrm{hPa}$ multiplied by the Coriolis parameter over $\left(10^{\circ}-55^{\circ} \mathrm{N}, 100^{\circ}-160^{\circ} \mathrm{E}\right)$ for $1979-2014$ (detrended), based on JRA-55. The mode explains 35\% of the variance. Panels (a, c) are based on JRA-55, and (b) is based on CMAP. For (d), TC occurrence is defined as the duration for which TCs are centered within $500 \mathrm{~km}$ from each grid point in a season, based on the best track data of the Regional Specialized Meteorological Center Tokyo-Typhoon Center. TCs and TC-originated extratropical cyclones with maximum wind speed exceeding $17.2 \mathrm{~m} \mathrm{~s}^{-1}$ are examined. Stippling indicates the $>95 \%$ confidence level, based on the $t$-test.

latitude Northwest Pacific in summer, a barotropically unstable mode and Rossby wave propagation from the tropics constitute the PJ pattern. A problem was that the prevailing winds in the upper troposphere over the summer Northwest Pacific are northeasterly, preventing stationary Rossby waves from propagating poleward. Poleward Rossby-wave dispersion is, however, possible in the lower troposphere (Kosaka and Nakamura, 2006). Kosaka and Nakamura (2010) and Hirota and Takahashi (2012) suggested that the PJ pattern is an internal regional mode of the atmosphere, fueled by tropical convective variability and gaining energy also from the background state via barotropic and baroclinic energy conversion. The anomalous circulation feeds back to tropical convective anomalies by dynamically inducing vertical motion. In the midlatitudes, there is a similar feedback between latent heating and the PJ circulation: local latent heating is both a cause of circulation formation ( $\mathrm{Lu}$ and Lin, 2009; Sun et al., 2010) and a result of the anomalous circulation through horizontal temperature advection (Kosaka et al., 2011). A variety of external perturbations, both in and out of the tropics, can trigger the PJ pattern (Arai and Kimoto, 2008; Hirota and Takahashi, 2012).

\subsubsection{SST forcing}

The local correlation between SST and precipitation anomalies of the PJ pattern is weak over the TNW Pacific (Wang et al., 2005; Wu et al., 2009a; Lu and Lu, 2014) and even negative over the SCS (Fig. 5), challenging Nitta's 


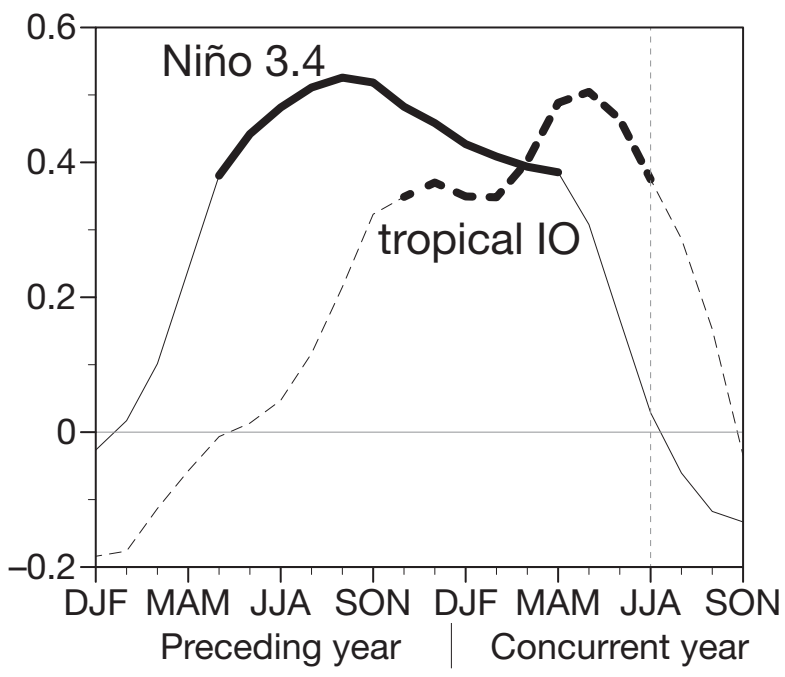

Fig. 6. Lag correlations of the summer PJ index (leading principal component for Fig. 5) with Niño3.4 (solid) and tropical IO $\left(20^{\circ} \mathrm{S}-20^{\circ} \mathrm{N}, 40^{\circ}-100^{\circ} \mathrm{E}\right.$; dashed) SST (detrended; threemonth running averaged). Thick curves represent the $>95 \%$ confidence level, based on the $t$-test.

hypothesis of local SST forcing. The PJ pattern is not significantly correlated with the concurrent ENSO index (Kosaka and Nakamura, 2006), but with ENSO in the preceding winter (Fig. 6; Wang et al., 2003). The impact of ENSO on the summer East Asian monsoon in ENSO decay years has been related to the PJ pattern (Huang et al., 2004). The tropical lobe of the PJ pattern in post-El Niño summer is the AAC with suppressed convection over the TNW Pacific (Fig. 5). The latter is often called the Philippine Sea AAC (Wang et al., 2000, 2003), but we note that it extends into the North IO with easterly wind anomalies on the south flank (Fig. 7a), enabling inter-basin interactions between the IO and Northwest Pacific. The western extent of the AAC reaches the Bay of Bengal and India, and northeasterly anomalies over the Arabian Sea appear to be part of the anti-symmetric pattern across the equator tied to the Southwest IO warming induced by the downwelling ocean Rossby wave (section 2.1). Regarding the oceanic anchor for the AAC, there are two hypotheses pointing to SST anomalies of the TNW Pacific and tropical IO, respectively.

In boreal winter of an El Niño event, an AAC develops rapidly east of the Philippines (Fig. 2b; Zhang et al., 1996) and is coupled with local SST (Wang et al., 1999, 2000). The AAC cools the ocean on the southeastern flank by strengthening the prevailing northeast trade winds. The ocean cooling suppresses atmospheric convection, reinforcing the AAC with a Rossby wave response. Alternatively, Stuecker et al. $(2013,2015)$ suggested that nonlinear interactions of atmospheric response to slowly evolving SST anomalies of the eastern tropical Pacific with the background annual cycle dominate and cause the rapid growth of the TNW Pacific AAC. This nonlinear mechanism explains the mysterious biennial tendency of atmospheric variability over the TNW Pacific (Li and Wang, 2005), e.g., the rapid transition from negative $\mathrm{JJA}(0)$ to positive $\mathrm{JJA}(1)$ anomalies of atmospheric pressure (Fig. 2b). This so-called combination mode effect is weak in post-ENSO summer when eastern Pacific SST anomalies have dissipated (M. Stuecker et al., 2015, personal communication).

The TNW Pacific air-sea coupling helps the AAC to persist but requires background northeasterly winds for positive feedback. In summer, the trade winds retreat eastward over the TNW Pacific (Fig. 1), limiting negative SST anomalies and the local air-sea feedback to a narrow region east of $140^{\circ} \mathrm{E}$ (Fig. 7a). Wang et al. (2003) suggested that the local coupling can help the AAC to persist from winter to summer. Difficulties extending this hypothesis to summer include the weakening and contraction of the negative SST anomalies (Fig. 2a) associated with the eastward retreat of the easterly trade wind regime, reducing the relative importance of airsea interaction in the easterly regime (Wu et al., 2010).

The second hypothesis, called the IO capacitor effect, considers the IO memory of ENSO influence. Recognizing that the El Niño-induced IO warming persists through summer (Fig. 2), Yang et al. (2007) suggested that it anchors the TNW Pacific AAC like a discharging capacitor. Xie et al. (2009) proposed a discharging mechanism for this IO capacitor. The IO warming excites a Matsuno-Gill-type response in tropospheric temperature, with a Kelvin wave wedge penetrating into the equatorial western Pacific (Fig. 7b). The warm equatorial Kelvin wave is accompanied by surface Ekman convergence on, and divergence off, the equator, thereby suppressing convection over the TNW Pacific (Fig. 7a). Terao and Kubota (2005) considered a similar mechanism but emphasized the inter-basin gradient between the IO warming and a developing La Niña in the equatorial Pacific (Yun et al., 2013). An apparent paradox is that the couplet of AAC and suppressed convection in the western Pacific is found only on the northern flank of the tropospheric Kelvin wave, although the Kelvin wave itself is symmetric about the equator (Fig. 7). This interhemispheric asymmetry arises because convection is stronger in the summer than winter hemisphere, and a strong convective feedback preferentially amplifies the Kelvin wave perturbations in the summer NH (Xie et al., 2009).

AGCM experiments show that the IO warming and TNW Pacific cooling contribute cooperatively to the summer TNW Pacific AAC (Ohba and Ueda, 2006; Wu et al., 2014). Wu et al. (2010) found that the AAC is mainly due to local airsea interaction in early summer but the IO effect dominates in the mid to late summer. A caveat is that AGCMs tend to exaggerate the local SST effect by simulating a positive local SST-precipitation relationship over the TNW Pacific, while the correlation is insignificant in observations (Wang et al., 2005; Wu and Kirtman, 2007). In a CGCM experiment, suppressing tropical IO SST variability reduced the intensity of the summer TNW Pacific AAC by roughly 50\% (Chowdary et al., 2011). It remains to be investigated what accounts for the other $50 \%$ of the AAC intensity-a question to be revisited in section 3 . Therein, we propose a unifying view that combines the local air-sea interaction hypothesis of Wang et 
(a) SST, $10 \mathrm{~m}$ wind velocity

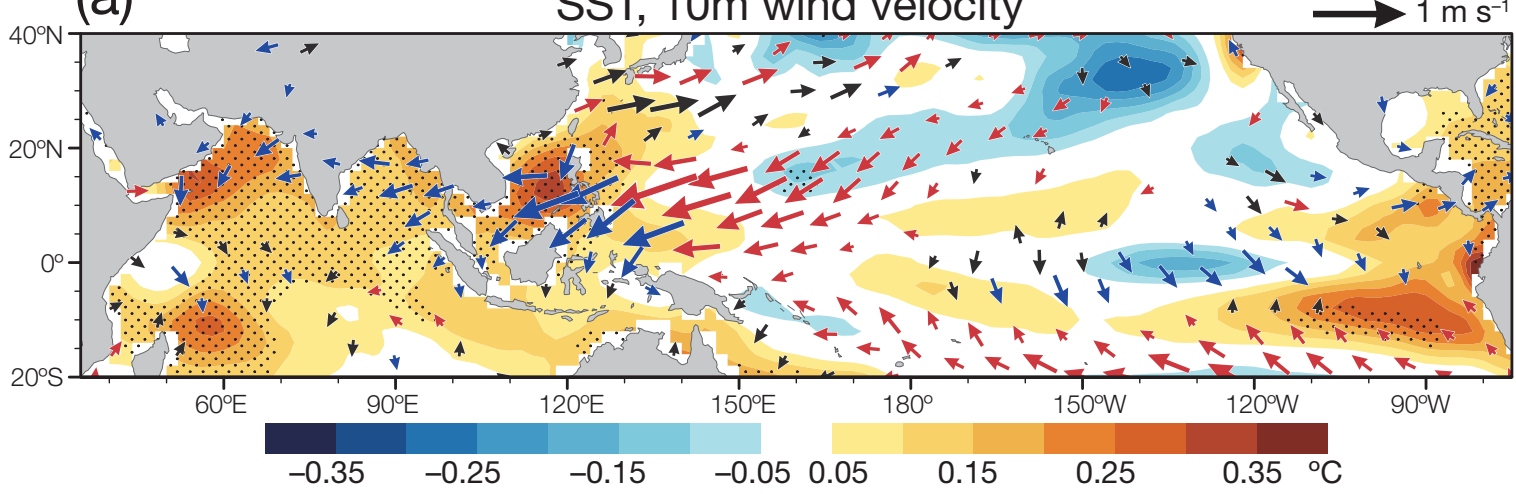

(b)

Precipitation, tropospheric temperature (normalized)

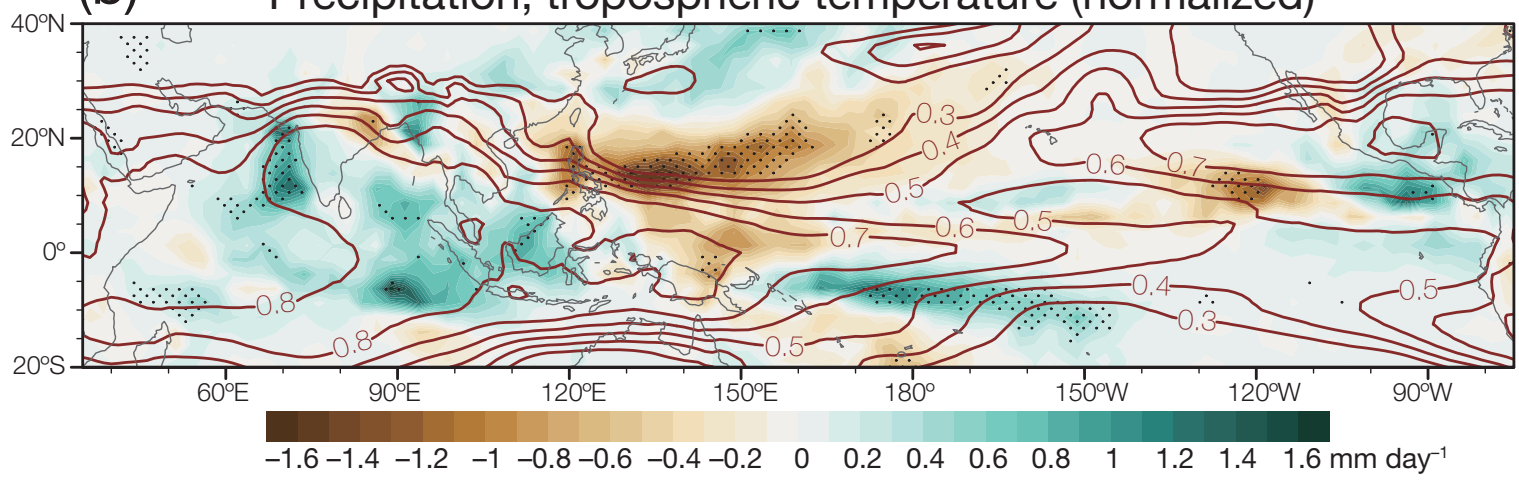

Fig. 7. JJA anomalies of (a) SST (shading), surface wind velocity (arrows), (b) precipitation (shading) and normalized tropospheric (850-250 $\mathrm{hPa}$ mean) temperature (contours with an interval of 0.1 ; contours within \pm 0.3 are omitted) regressed against Niño 3.4 SST in the preceding NDJ for 1978/79-2009/10 [based on JRA-55 (surface wind and tropospheric temperature), CMAP, and ERSST.v3b (Smith et al. 2008); 8-year high-pass filter has been applied beforehand; stippling indicates the $>95 \%$ confidence level, based on the $t$-test, for shaded anomalies; red (blue) arrows indicate where the wind anomalies strengthen (weaken) climatological winds by more than $0.1 \mathrm{~m} \mathrm{~s}^{-1}$ ].

al. (2003) and the IO capacitor of Xie et al. (2009).

Statistically, eastern tropical Pacific SST anomalies diminish in JJA(1) (Fig. 2a) but individual ENSO events differ among themselves during the decay. For example, a strong La Niña event developed in 1998 summer (with Niño3.4 SST at $-1.2^{\circ} \mathrm{C}$ ) following a record El Niño. Such variability in the SST gradient between the IO and tropical Pacific contributes to the TNW Pacific AAC (Terao and Kubota, 2005; Chen et al., 2012; Cao et al., 2013; Xiang et al., 2013). Recent studies have also suggested a contribution from the tropical Atlantic (Rong et al., 2010; Hong et al., 2014; Chen et al., 2015; Yu et al., 2015). All these-IO warming, the TNW Pacific AAC, tropical Pacific cooling, and tropical Atlantic warming-may not be mutually independent (Kug and Kang, 2006; Stuecker et al., 2015; Li et al., 2015c), highlighting the need for a generalized view of inter-basin interactions.

\subsection{Impacts on terrestrial climate}

\subsubsection{Northwest Pacific TCs and Indian rainfall}

Coherent anomalies of summer TC activity over the Northwest Pacific accompany the PJ pattern (Fig. 5d; Choi et al., 2010; Kim et al., 2012). In post-El Niño summer, the AAC is unfavorable for TC development. TC genesis decreases over most of the TNW Pacific while slightly increasing over the SCS, consistent with the pattern of vertical wind shear change (Du et al., 2011). TC occurrences drop in a region centered on Okinawa, with significantly reduced landfall on the coasts of eastern China and Korea (Fig. 5d; Wang et al., 2013). These TC anomalies are captured in highresolution AGCM simulations, pointing to the importance of SST boundary conditions (Mei et al., 2015). Using a regional atmospheric model, Zhan et al. (2011) showed that eastern IO SST anomalies affect TC genesis over the TNW Pacific by modulating the western Pacific summer monsoon via the equatorial Kelvin wave.

The TNW Pacific AAC extends into the North IO, affecting South Asia (Mishra et al., 2012). In post-El Niño summer, most of the South Asian region receives normal to abovenormal rainfall despite weak monsoon winds (Park et al., 2010; Chowdary et al., 2013). The anomalous warm SST promotes evaporation and increases atmospheric moisture over the North IO (e.g., Saha, 1970). Enhanced moisture transport (Izumo et al., 2008) and moist stability increase rainfall in the Western Ghats and southern peninsular of India (Yang et al., 2007; Park et al., 2010), while the westward extension of the TNW Pacific AAC acts to reduce rainfall over the eastern 
Indo-Gangetic Plain (Chowdary et al., 2013).

\subsubsection{Summer variability over East Asia}

The PJ pattern provides a pathway for tropical influences on the East Asian summer monsoon. In the polarity shown in Fig. 5 (corresponding to a post-El Niño summer), the PJ pattern brings anomalously wet and cool conditions to the Yangtze River valley, Korea, and Japan. It prevents the seasonal northward migration of the Northwest Pacific subtropical high and Mei-yu rainband, resulting in a prolonged rainy season with reduced sunshine in these regions. The mega El Niño of 1997/98 caused the great Yangtze River flood in 1998 through the PJ pattern (Chowdary et al., 2011).

Huang and $\mathrm{Wu}$ (1989) suggested that summer rainfall anomalies in East Asia depend on the phase of the ENSO cycle, relating the differences between the ENSO developing and decay summers to tropical convection over the South China and Philippine seas. Subsequent studies (Shen and Lau, 1995; Chang et al., 2000; Wang et al., 2000; Wu et al., 2003) showed that in post-El Niño summer the TNW Pacific AAC causes above-normal rainfall in the Yangtze River valley. The relationship between East Asian summer rainfall and ENSO is unstable over time (Wu and Wang, 2002; Ye and Lu, 2011), possibly due to the slow modulations by variations in ENSO amplitude and/or type (Xie et al., 2010; Feng et al.,
2011; Yuan and Yang, 2012; Li et al., 2014). Further complications include apparent asymmetry between polarities in the leading mode of East Asian summer rainfall variability (Hsu and Lin, 2007).

In post-El Niño summer, anomalous vertical motions associated with the PJ pattern cause positive surface temperature anomalies in southern China and negative anomalies in northeast China by changing shortwave radiation and adiabatic warming (Hu et al., 2011). The circulation anomalies also cause more frequent heat waves than normal across the southern Yangtze River Valley in late summer (Hu et al., 2012). In Japan, the PJ pattern is one of dominant modes for summer temperature (Fig. 5c; Wakabayashi and Kawamura, 2004; Yasunaka and Hanawa, 2006), contributing to heat waves (e.g., in 2004) and extreme cool summers (e.g., in 1993). The record cool and wet summer of 1993 caused a major rice harvest failure in Japan, pushing the nation to open its domestic rice market.

\section{A coupled perspective}

In post-El Niño summer, the warming of the North IO and SCS causes the AAC via the warm tropospheric Kelvin wave (section 2.2), while anomalous easterly winds on the southern flank of the AAC cause the second warming of the North IO and SCS. The circular argument indicates that the two are a

\section{(a) SST, tropospheric temperature}

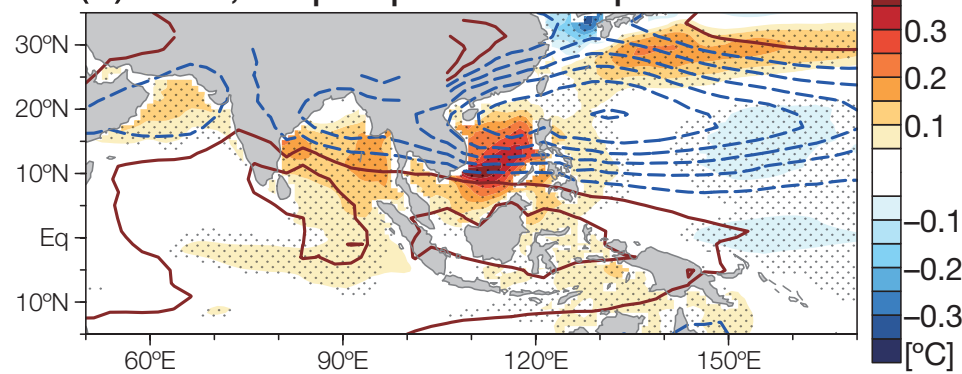

(c) Lag correlations

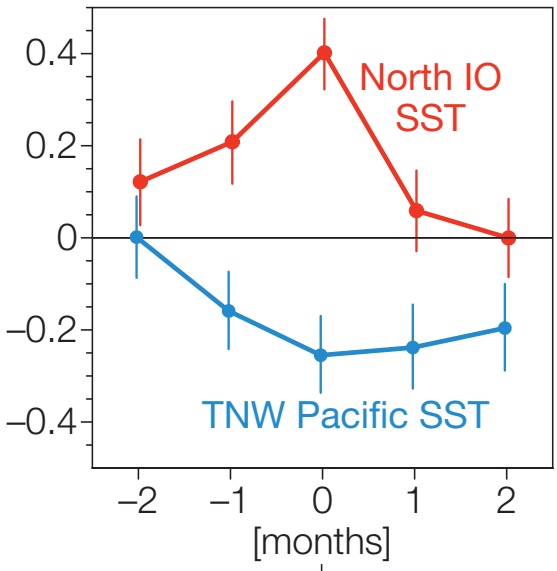

atmos. lead SST lead

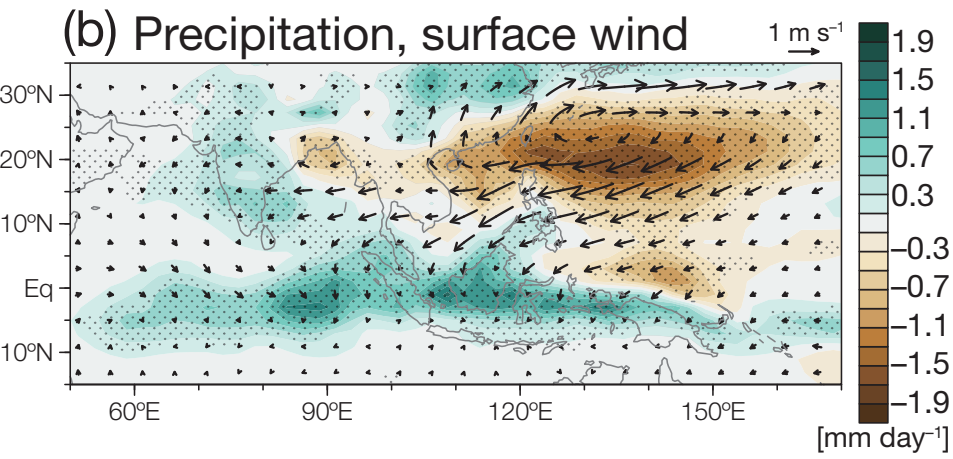

Fig. 8. Air-sea coupling of the IPOC mode in a 200-year partial coupling experiment called NoENSO, which artificially suppresses SST variability over the tropical eastern Pacific: ( $a, b)$ anomalies of (a) SST (shading), normalized tropospheric temperature (contours for $\pm 0.05, \pm 0.15, \pm 0.25, \ldots{ }^{\circ} \mathrm{C}$ ), (b) precipitation (shading) and surface wind (arrows) regressed against the leading principal component of monthly $850 \mathrm{hPa}$ vorticity over $\left(0^{\circ}-60^{\circ} \mathrm{N}, 100^{\circ}-160^{\circ} \mathrm{E}\right)$ for JJA (stippling indicates the $>95 \%$ confidence level of shaded fields, based on the $t$-test); (c) lag cross-correlation of the corresponding principal component with SST in the northern IO $\left(0^{\circ}-25^{\circ} \mathrm{N}, 60^{\circ}-120^{\circ} \mathrm{E}\right.$; red) and TNW Pacific easterly regime $\left(10^{\circ}-20^{\circ} \mathrm{N}, 150^{\circ}-170^{\circ} \mathrm{E}\right.$; blue $)$ [error bars represent the $95 \%$ confidence intervals; based on Kosaka et al. (2013) with slight model updates]. 
coupled phenomenon. Kosaka et al. (2013) identified such a coupled mode that involves inter-basin interaction between the North IO and TNW Pacific, using the Pacific OceanGlobal Atmosphere partial coupling framework, where SST variability in the tropical Pacific is strongly damped towards zero ("NoENSO" experiment).

Even without ENSO, the PJ pattern is coupled with positive SST anomalies over the North IO and SCS, along weak negative anomalies in the easterly regime of the TNW Pacific (Fig. 8a). Negative precipitation anomalies peak on the boundary between positive and negative SST anomalies in the westerly and easterly regimes of the TNW Pacific, respectively. The anomalous diabatic cooling over the TNW Pacific forces an AAC as a cold atmospheric Rossby wave that propagates into the North IO. The associated easterly anomalies on the southern flank (Fig. 8b) weaken the monsoon westerlies and reduce surface evaporation, causing the North IO and SCS to warm. The ocean feedback to the AAC is nonlocal, as the spatial correlation between SST and precipitation anomalies is weak (Fig. 8). By forcing tropospheric temperature to follow a moist adiabatic profile in the vertical direction (Neelin and Su, 2005), the North IO warming then excites a warm atmospheric Kelvin wave (Fig. 8a), suppressing convection and energizing the AAC over the TNW Pacific. The inter-basin air-sea interaction supports positive feedback between the North IO warming and AAC. Indeed, the crosscorrelation between the PJ pattern and North IO SST peaks at zero lag (Fig. 8c), indicating positive feedback. As another manifestation of the ocean-atmosphere feedback, both the magnitude and temporal persistence of PJ variability substantially increases in the coupled relative to the atmospheric experiment (Kosaka et al., 2013).

Kosaka et al. (2013) focused on the IO-PJ coupling and suggested the prevailing monsoon westerlies as the necessary condition. Here, we extend their analysis to examine the preseason evolution. Note that equatorial Pacific SST anomalies are kept near zero all the time in the NoENSO experiment. The JJA IO-PJ coupling is preceded by negative anomalies of SST and precipitation over the TNW Pacific (Fig. 9a). In the pre-season (April-May) TNW Pacific, negative SST anomalies are collocated with northeasterly wind anomalies on the southeastern flank of an AAC that extends into the North IO (Fig. 10a). The interaction of negative SST anomalies and the AAC under the northeast trades over the spring TNW Pacific constitutes positive feedback, as envisioned by Wang et al. (2000). The seasonal variation in the background wind over the TNW Pacific alters the type of feedback that prevails in different seasons. The monsoon westerly regime appears in the North IO in May and expands eastward through the SCS into the TNW Pacific (Fig. 9b). The eastward seasonal expansion of the monsoon westerlies leaves a clear signature in the boundary between the expanding positive and contracting negative SST anomalies in the coupled IO-TNW Pacific mode (Fig. 9a). The easterly anomalies of the AAC induce negative SST anomalies under the easterly trades but create positive anomalies under the monsoon westerlies (Fig. 10b). This seasonally evolving coupled mode unifies the local air- sea interaction mechanism of Wang et al. (2000) that dominates in spring under the northeast trades over the TNW Pacific, and the IO capacitor effect of Xie et al. (2009) that takes over in summer under the southwest monsoon.

This Indo-western Pacific inter-basin coupling itself does not require ENSO forcing, but El Niño excites this mode by inducing the IO warming (Kosaka et al., 2013) and TNW Pacific cooling (Wang et al., 2013; Stuecker et al., 2015) as initial perturbations. This coupled mode generalizes the capacitor concept and constitutes an Indo-western Pacific ocean capacitor (IPOC). In the peak phase of ENSO, the tropical Pacific is the center of action featuring, globally, the most pronounced anomalies of SST, precipitation, and surface wind. By contrast, in JJA(1), the discharging IPOC shifts the ENSO's center of action to the Indo-TNW Pacific region, where the most pronounced and coherent anomalies are found. The positive feedback among the TNW Pacific cooling, North IO warming and AAC prolongs ENSO anomalies and explains why the decay of El Niño follows the spatiotemporal pattern of the IPOC mode, both in JJA(1) (Fig. 7) and the pre-season (Fig. 10a). Thus, the IO "basin mode" (Yang et al., 2007) is truly a dynamic mode, as the inter-basin interaction sustains it against dissipation. While observations suggest cross-basin ocean-atmosphere interaction (Du et al., 2009; Wang et al., 2013), the NoENSO partial coupling experiment of Kosaka et al. (2013) shows that IPOC is an intrinsic mode of the region with a distinctive seasonal evolution dictated by monsoon. The PJ pattern is an atmospheric internal mode ( $\mathrm{Lu}$ et al., 2006) but energized by ocean coupling and ENSO forcing. The seasonally varying IPOC brings seasonal predictability to the region (section 4). The mode also emerges from the inter-member spread of ensemble seasonal predictions (Li et al., 2012) as differences in initial conditions grow on the IPOC feedback.

\section{Predictability}

\subsection{Tropics}

CGCMs, properly initialized with observations, show skill in predicting precipitation and circulation anomalies over the TNW Pacific during summer following El Niño at monthly to seasonal leads (Liang et al., 2009; Wang et al., 2009; Chowdary et al., 2010; Lee et al., 2011). Figure 11 compares 11-model mean forecasts with observations in composites of three post-El Niño summers with a significant IO warming (in 1983, 1992 and 1998). At one month lead (initialized on $1 \mathrm{May}$ ), the multi-model ensemble captures the salient features of the IPOC mode, i.e., the collocated anomalies of SST increase and weakened monsoon winds over the North IO and SCS, the warm tropospheric Kelvin wave wedge into the western Pacific, as well as the AAC that extends from the TNW Pacific into the North IO. Models have good skill in predicting summer monsoon rainfall over the Indo-TNW Pacific, as well as South and East Asia (Fig. 11d). At three-month (initialized on 1 March) lead, significant skill remains in predicting the AAC and rainfall anoma- 
lies over the TNW Pacific (Chowdary et al., 2010; Li et al., 2012, Lu et al., 2012; Jiang et al., 2013).

The IO effect on the prediction is studied with a "NoTIO" experiment, where climatological SST is prescribed over the tropical IO. Figure 12 shows the JJA(1) composite difference in circulation, precipitation and SLP between control (CTL) and NoTIO runs in one-month lead forecasts. Seasonal anomalies are strengthened by IO SST variability. Specifically, the IO warming increases local precipitation and induces an AAC with reduced precipitation over the TNW Pacific. The CTL-NoTIO differences clearly illustrate the importance of tropical IO air-sea interaction in predicting circulation and rainfall over the Indo-TNW Pacific region. An interactive tropical IO extends the useful anomaly correlation coefficient $(r>0.5)$ in predictions of circulation anomalies over the TNW Pacific by 1-2 months (Chowdary et al., 2011).

\subsection{Midlatitudes}

To the extent that atmospheric circulation and rainfall anomalies are predictable over the IO-TNW Pacific, the PJ pattern allows these tropical anomalies to influence the midlatitude East Asian and Northwest Pacific region and conceivably enhances predictability there. Indeed, prediction studies show some skill, i.e., increased rainfall and southwesterly wind anomalies over eastern China and the south of Japan in post-El Niño summer (Fig. 11). Generally, however, the predictability in East Asia is limited, both due to model errors in simulating the Mei-yu rain band and to pronounced internal variability of the atmosphere that is unpredictable at monthly and longer leads.

For the summer of 2010, a multi-model ensemble pre- dicted a PJ mode but the prediction was verified only in the tropics: Monsoon rainfall intensified over the Arabian Sea and weakened over the TNW Pacific, typical of a post-El Niño summer. Deviating from the dipolar PJ pattern, however, Korea and Japan experienced extreme hot weather while northwest Pakistan was devastated by heavy floods. These floods are attributed to unusual atmospheric events in the tropics, with deep convection shifted from the Bay of Bengal to northern Pakistan (Houze et al., 2011; Pai and Sreejith, 2011; Webster et al., 2011). Midlatitude circulation triggered by a blocking high that caused the Russian heat wave also contributed to the Pakistan heavy rains downstream (Lau and Kim, 2012; Kosaka et al., 2012). Models show some skill in predicting the distinct seasonal rainfall anomalies in summer 2010 from the northern Arabian Sea to northern Pakistan, but this predictability comes from the tropical region (Chowdary et al., 2014). Models failed to predict the extreme intensity of northern Pakistan rainfall and positive precipitation anomalies in western Pakistan due to the inadequate representation of subtropical circulation, such as the Silk Road pattern.

The Silk Road pattern is the wavy component of the summer circumglobal teleconnection pattern in the Eurasian sector, trapped in the waveguide of the subtropical Asian jet (Fig. 13; Wu, 2002; Enomoto, 2004; Ding and Wang, 2005; Kosaka et al., 2009). In summer 2010, the Silk Road pattern caused an anomalous anticyclonic circulation over Japan and a cyclonic circulation over west-central Asia around $40^{\circ} \mathrm{N}$. Coupled models can simulate the stationary wave pattern of the Silk Road teleconnection (anchored by zonal variations of the Asian jet) but not the temporal phase (Kosaka et al., 2012; Chowdary et al., 2014). This indicates that the Silk
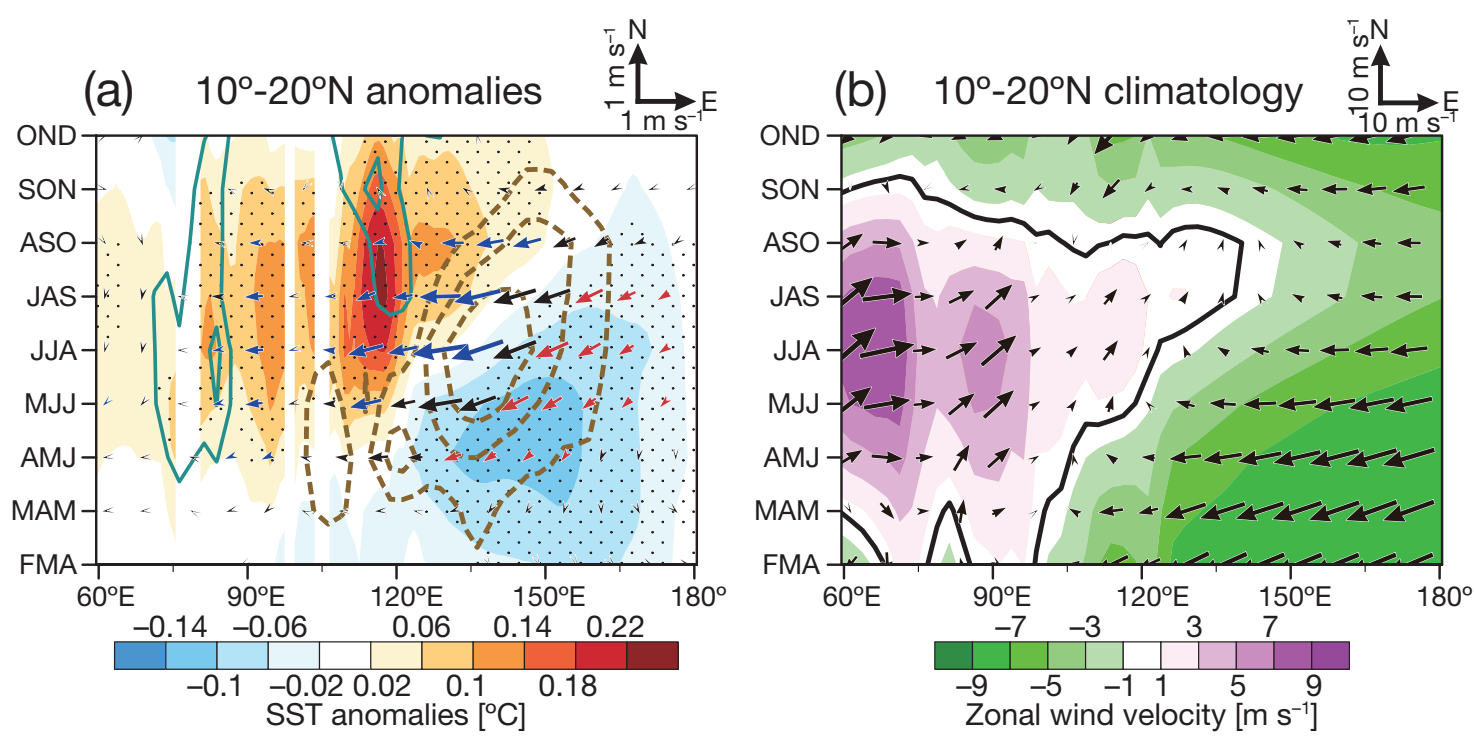

Fig. 9. Seasonal evolution of the IPOC mode in the 200-year NoENSO run: (a) SST (shading), precipitation (contours for $\pm 0.2, \pm 0.4, \pm 0.6, \ldots \mathrm{mm} \mathrm{d}^{-1}$ ) and $10 \mathrm{~m}$ wind (arrows) anomalies averaged over $10^{\circ}-20^{\circ} \mathrm{N}$ regressed against the leading principal component of JJA seasonal-mean $850 \mathrm{hPa}$ vorticity over $\left(0^{\circ}-60^{\circ} \mathrm{N}, 100^{\circ}-160^{\circ} \mathrm{E}\right.$ ) (red and blue arrows indicate that the corresponding wind speed anomalies are greater than 0.1 and less than $-0.1 \mathrm{~m} \mathrm{~s}^{-1}$, respectively; stippling indicates the $>95 \%$ confidence level for SST anomalies, based on the $t$-test); (b) climatological $10 \mathrm{~m}$ wind velocity (arrows) and its zonal component (shading with zero contour; three-month sliding average applied). 


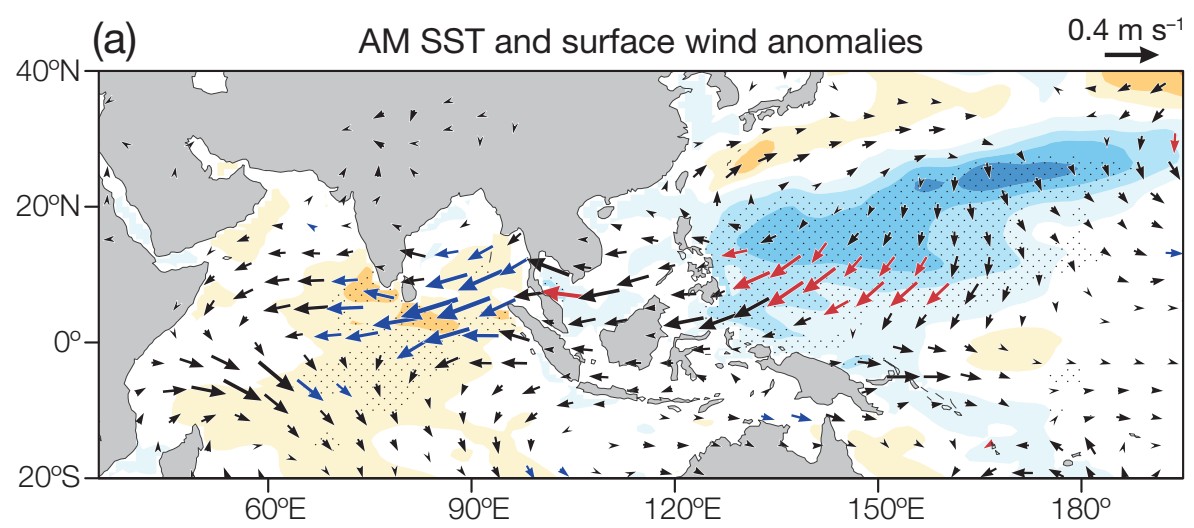

(b)

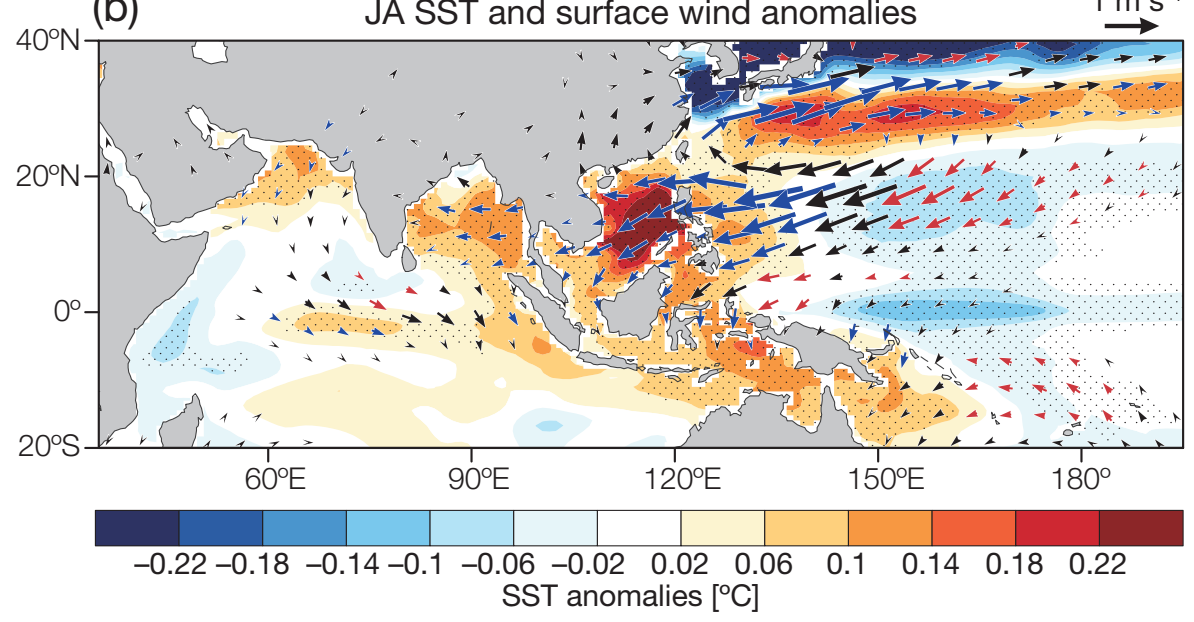

Fig. 10. As in Fig. 9a but horizontal maps for (a) preceding April-May and (b) concurrent JulyAugust [precipitation anomalies are omitted for clarity; red (blue) arrows indicate where the wind anomalies strengthen (weaken) climatological winds].

Road pattern is an internal mode of the midlatitude atmosphere, whereas the zonal-mean component of the summer circumglobal teleconnection pattern is correlated with developing ENSO (Ding et al., 2011) and hence is predictable (Lee et al., 2011, 2014). Because chaotic phase variations of the Silk Road pattern are not strongly tied to SST forcing, it limits the predictability at monthly and longer leads over East Asia even though the PJ pattern transmits predictable tropical influences. Some recent studies, however, suggest an association of the Silk Road pattern with Atlantic SST (Wu et al., 2009b; Yamaura and Tomita, 2011; Otomi et al., 2013). This is a potential source of predictability that can benefit midlatitude Asian countries.

\section{Interdecadal modulations}

ENSO teleconnections to the IO-TNW Pacific and East Asia show substantial interdecadal variations over the second half of the 20th century, a period of relatively abundant observations. The relationship of the East Asian summer monsoon and TNW Pacific AAC to the preceding ENSO was strong after the late 1970s but insignificant from the 1950s to 1970 s (Wu and Wang, 2002; Wang et al., 2008; Xie et al.,
2010). Consistent with the IO capacitor mechanism, the El Niño-induced IO warming persists through summer only after the 1970s as the thermocline in the tropical Southwest IO shoaled to strengthen thermocline feedback (Xie et al., 2010). Tracking the tropospheric Kelvin wave that connects the IO warming and western Pacific, tropospheric temperature in long-term sounding observations over Singapore shows a corresponding increase in correlation with ENSO. An AGCM forced with observed SST successfully simulated the increase in the ENSO-AAC correlation and AAC variance throughout the 1970s (Huang et al., 2010). Using an AGCM coupled with an ocean mixed layer, Ding et al. (2015) reproduced the interdecadal modulation in partial coupling experiments that restored SST towards observations over the equatorial Pacific.

Chowdary et al. (2012) used surface ocean-atmospheric observations along a busy shipping track across the North IO and SCS to extend the analysis back to 1871-the year of Suez Canal opening, which consolidated IO shipping lanes. The correlation between summer North IO SST and preceding winter ENSO was high at the turn of the 20th century and since the mid-1970s, but was low in between (Fig. 14a). The North IO SST modulations were accompanied by consistent 


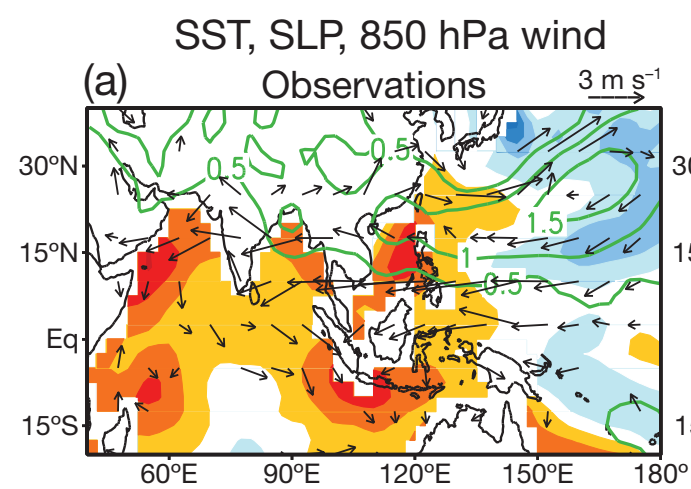

Precipitation, tropospheric temp

(b) Observations

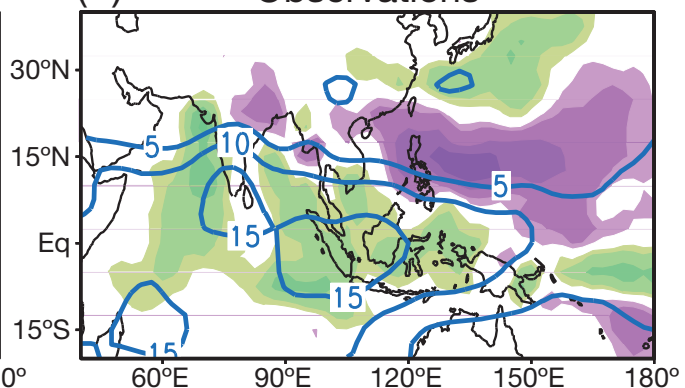

(c) MME seasonal predictions

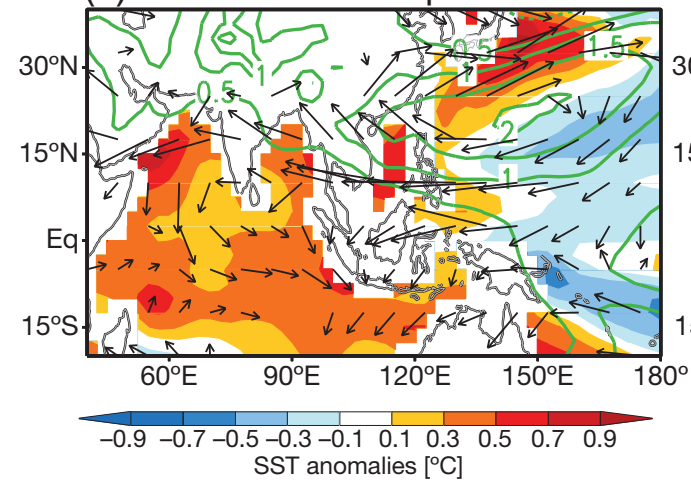

(d) MME seasonal predictions

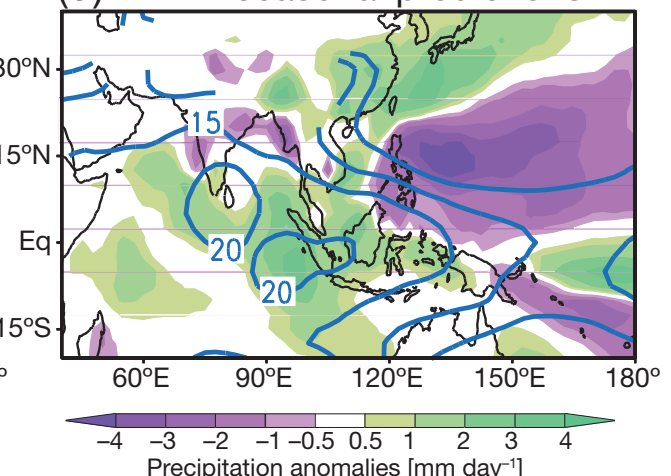

Fig. 11. Composited anomalies for JJA in 1983, 1992 and 1998 (summers following major El Niño events) based on $(\mathrm{a}, \mathrm{b})$ observations and $(\mathrm{c}, \mathrm{d})$ the multi-model ensemble mean of seasonal predictions by 11 coupled models initialized on 1 May: (a, c) SST (shaded; ${ }^{\circ} \mathrm{C}$ ), SLP (contours; every $0.5 \mathrm{hPa}$ ), $850 \mathrm{hPa}$ wind (vectors; magnitudes above $0.3 \mathrm{~m} \mathrm{~s}^{-1}$ are displayed); (b, d) precipitation (shaded; $\mathrm{mm} \mathrm{d}^{-1}$ ) and tropospheric temperature represented by 200-850 hPa thickness (contours; gpm). Reprinted from Chowdary et al. (2010).

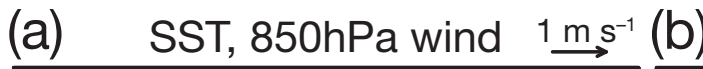
Precipitation, SLP

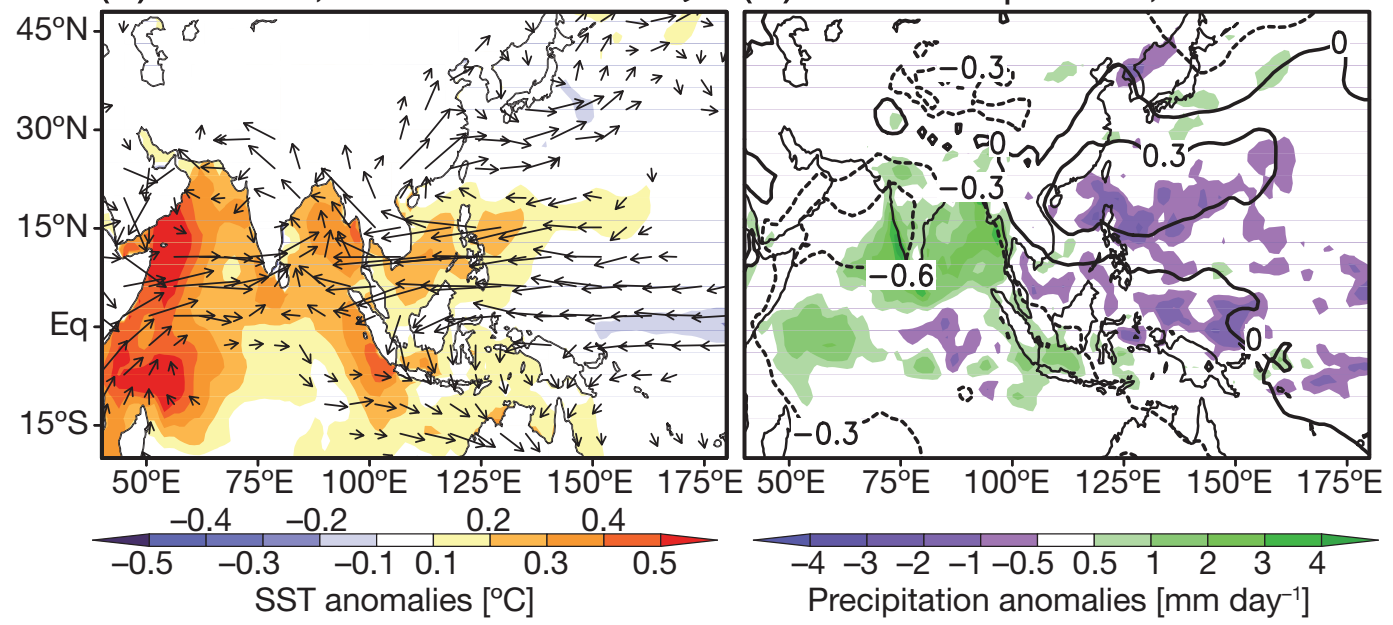

Fig. 12. JJA(1) differences in (a) SST (shaded; ${ }^{\circ} \mathrm{C}$ ) and $850 \mathrm{hPa}$ wind anomalies (arrows; magnitudes exceeding $0.3 \mathrm{~m} \mathrm{~s}^{-1}$ are displayed) and (b) precipitation (shaded; $\mathrm{mm} \mathrm{d}^{-1}$ ) and SLP (contours; hPa), between CTL and NoTIO predictions with a 1-month lead (initialized on 1 May) by the CGCM of Luo et al. (2008), based on the composites of three El Niño decay years (1983, 1992 and 1998).

modulations in local wind, as well as in remote pressure and rainfall over the TNW Pacific. Kubota et al. (2015) used station data of atmospheric pressure to reconstruct the PJ pattern from 1897 and found similar modulations in correlation with the preceding winter ENSO, with significant correlations before the 1910s, around the 1930s, and since the 1970s (Fig. 14c). As similar modulations happened before, the recent increase in correlation between the IPOC mode and ENSO 
appears to be due to natural variability, rather than to anthropogenic climate change (Zheng et al., 2011). In support of this notion, interdecdal modulations of the ENSO effect on Indo-TNW Pacific summer climate are common in climate model simulations under constant radiative forcing ( $\mathrm{Hu}$ et al., 2014). The interdecadal modulations indicate that the seasonal predictability of summer IO-WNP climate varies from one decade to another.

ENSO amplitude can affect the strength of ENSO teleconnection to the Indo-TNW Pacific region. The period, amplitude, spatial structure, and temporal evolution of El Niño events can cause significant changes in ENSO teleconnections (Diaz et al., 2001). When ENSO variance is high (at the turn of the 20th century and after the 1970s) (Fig. 14b), correlations of atmospheric anomalies in the Indo-TNW Pacific with ENSO are high (Chowdary et al., 2012; Kubota et al., 2015; Yang et al., 2015). Variations in El Niño to La Niña transition and the persistence of IO warming may also affect the TNW Pacific AAC in summer (Xie et al., 2010). For example, the intensified ENSO-PJ correlation in the 1930s is not associated with an ENSO amplitude increase, but rather with an increase in IO warming persistence (Fig. 14d). The Pacific Decadal Oscillation is an additional factor that can modulate the ENSO impact on Indo-TNW Pacific climate (Wang et al., 2008; Feng et al., 2014).

\section{Summary and outlook}

ENSO is a climate phenomenon that opens on the center stage of the equatorial Pacific. The last act of El Niño drama is played over the Indo-western Pacific in JJA(1) after the curtain falls on the main stage. The main cast of the last act includes the surface warming in the westerly monsoon regime of the Indo-western Pacific warm pool, and the AAC that ex- tends from the TNW Pacific into the North IO. Here, we have reviewed recent advances, with a historical perspective, in the investigation of how the last act is staged.

Our synthesis has revealed the IPOC mode sustained by inter-basin ocean-atmosphere interaction (Fig. 15). IPOC unifies two separate ideas for the post-El Niño summer AAC that emphasize either the sea surface cooling in the easterly trade regime of the TNW Pacific (Wang et al., 2000), or the sea surface warming in the westerly monsoon regime over the IO and SCS (Xie et al., 2009). The zonal contrast between the IO warming and Pacific cooling was previously recognized (Terao and Kubota, 2005; Ohba and Ueda, 2006) as important for the AAC, but the discussion was limited to an atmospheric, not coupled, perspective. The coupled perspective further recognizes that the North IO warming and TNW Pacific cooling are caused by the easterly wind anomalies on the southern flank of the AAC that weaken the westerly monsoon and strengthen the easterly trade winds (Du et al., 2009). The interaction of the SST anomalies and AAC yields positive feedback.

The IPOC is an internal mode arising from inter-basin ocean-atmosphere feedback, as illustrated by the NoENSO partial coupling experiment of Kosaka et al. (2013). In midsummer, IO SST anomalies are the major cause of the AAC (Wu et al., 2010) as the easterly trade regime retreats eastward over the TNW Pacific, reducing the area of the SST cooling. The free IPOC mode shows a seasonal evolution preceded by the TNW Pacific cooling-AAC coupling in spring. Remarkably, the TNW Pacific cooling-AAC coupling in the free mode happens to resemble what is observed during the El Niño decay in spring (Wang et al., 2000, 2003). This indicates that ENSO preferentially excites the IPOC mode because of the reduced damping. In addition to the TNW Pacific cooling, the El Niño-induced downwelling Rossby waves in

(a)

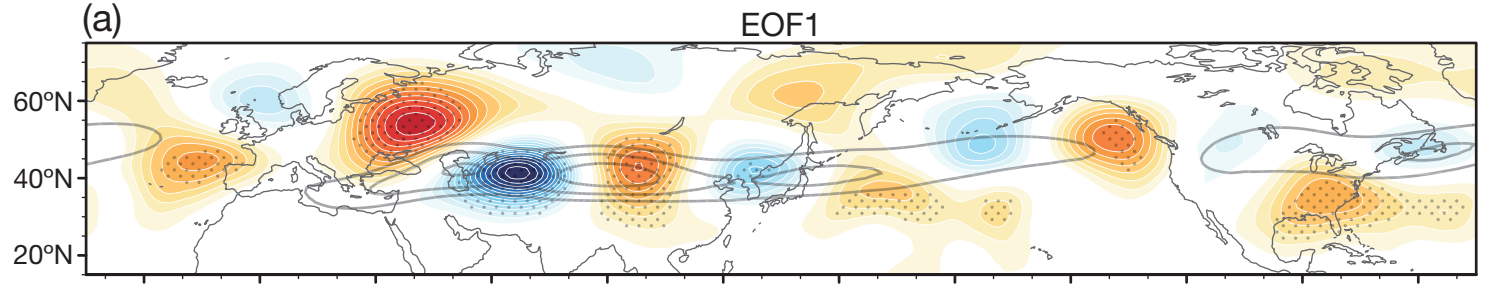

(b) EOF2

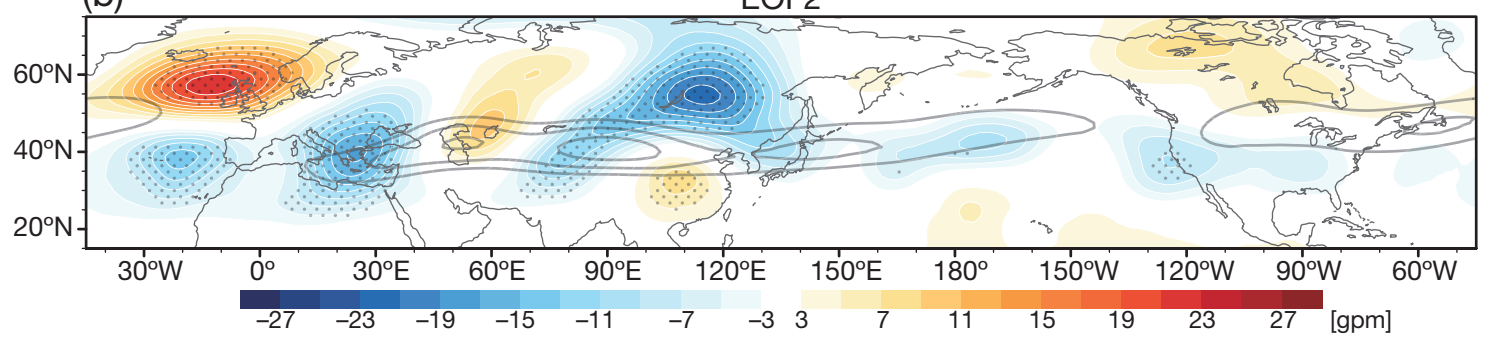

Fig. 13. Structure of the Silk Road pattern: $200 \mathrm{hPa}$ geopotential height anomalies (shading) regressed against the (a) leading and (b) second principal components of JJA-mean $200 \mathrm{hPa}$ meridional wind velocity over $\left(30^{\circ}-50^{\circ} \mathrm{N}, 30^{\circ}-\right.$ $130^{\circ} \mathrm{E}$ ), which explain $40.2 \%$ and $20.7 \%$ of variance, respectively (stippling represents the $>95 \%$ confidence level, based on the $t$-test; grey contours indicate JJA climatological zonal wind velocity at $200 \mathrm{hPa}$ for 20,25 and $30 \mathrm{~m} \mathrm{~s}$; based on JRA-55 for 1979-2014) (detrended). 
the South IO also help initialize the IPOC mode by anchoring a meridional anti-symmetric wind pattern with anomalous easterlies over the Arabian Sea (Fig. 15; Du et al., 2009). The easterly wind anomalies, induced by the ocean Rossby waves, and as part of the AAC, cause the second warming of the North IO and SCS upon the onset of the westerly monsoon. The second warming manifests the unstable interaction of the North IO and AAC.
An atmospheric bridge allows ENSO to imprint upon the SST in other ocean basins (Lau and Nath, 1996; Alexander et al., 2002). The IO capacitor emphasizes that IO SST anomalies induced by the atmospheric bridge outlast ENSO forcing itself and discharge regional climatic influences (Yang et al., 2007; Xie et al., 2009). Our work here extends the ocean capacitor concept by revealing the coupled ocean-atmosphere feedback beyond a simple persistence due to ocean thermal

(a) Lag correl of North IO shiptrack SST with NDJ(0/1) Niño3.4 SST

Dec (1)
Sep (1)
Jun (1)
Mar (1)
Dec (0)
Sep (0)
Jun (0)
Mar (0)

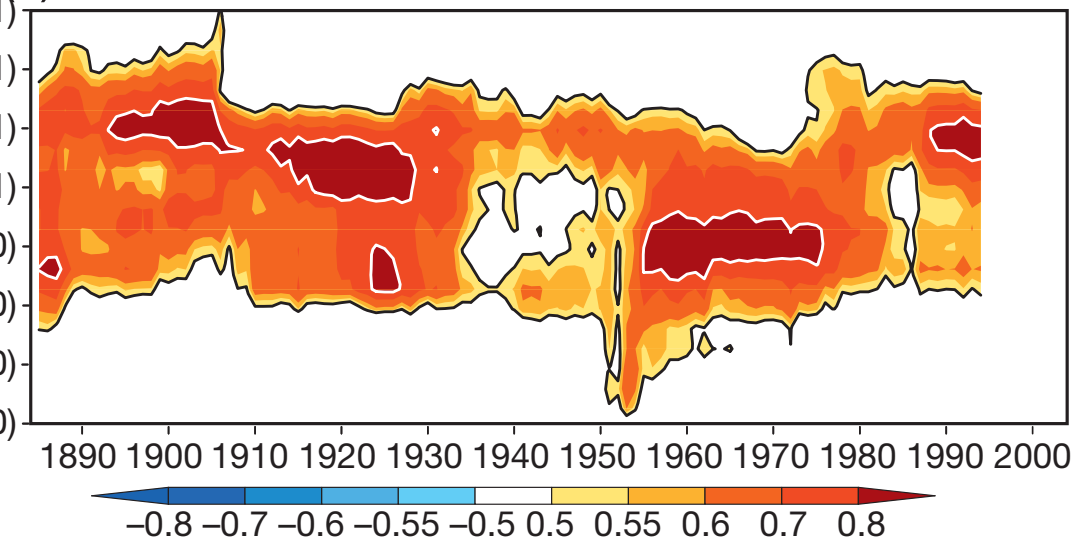

(b) Variance of NDJ(0/1) Niño3.4 SST \& DJF(0/1) SOI

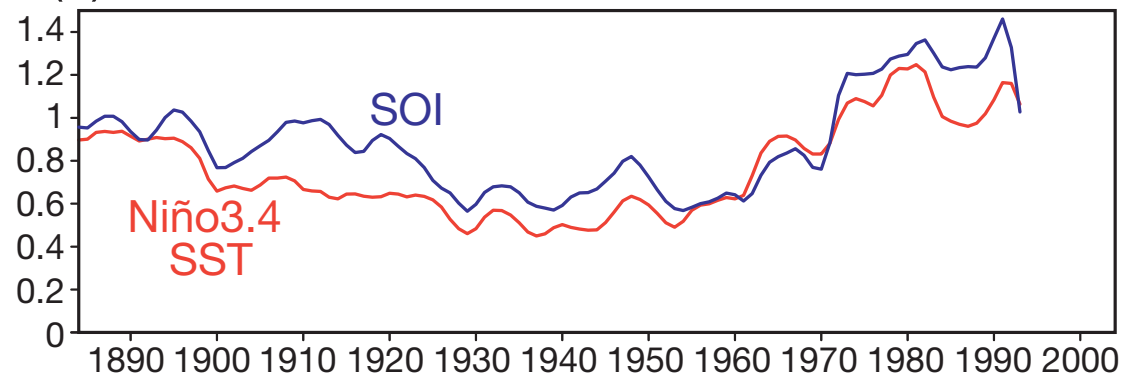

(c) Correl of the PJ index \& North IO shiptrack SST with DJF(0/1) SOI

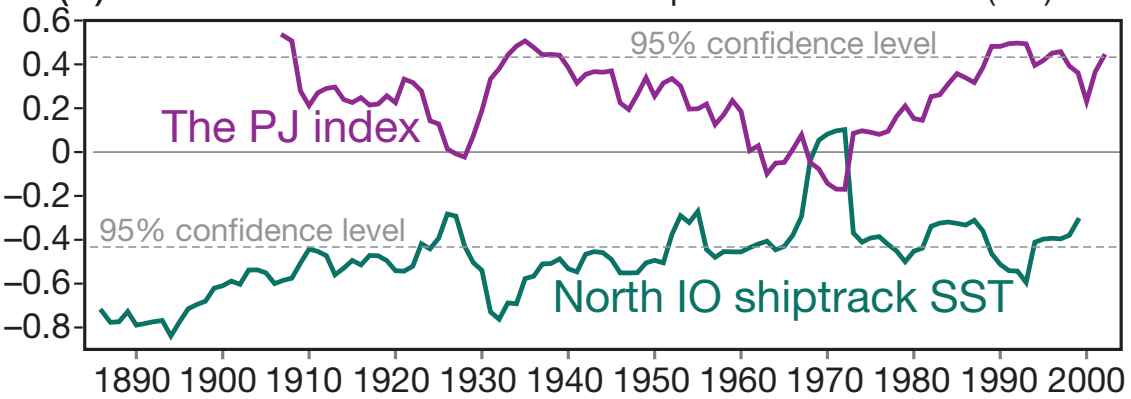

Fig. 14. (a) Lag correlation in a 21-year sliding window of North IO SST averaged along a shipping track with respect to $\mathrm{ND}(0) \mathrm{J}(1)$ Niño3.4 SST (black contours represent the $95 \%$ confidence level and white contours represent correlations of 0.8). (b) 21-year sliding variance of $\mathrm{ND}(0) \mathrm{J}(1)$ Niño3.4 SST (red) and $\mathrm{D}(0) \mathrm{JF}(1)$ Southern Oscillation Index (SOI; scaled by 2.8; blue). (c) 21-year sliding correlation of the PJ index [difference of normalized station pressure records between Yokohama, Japan and Hengchun, Taiwan, in JJA; Kubota et al. (2015); purple] and North IO shipping track SST in JJA(1) with SOI in $\mathrm{D}(0) \mathrm{JF}(1)$. Note that the PJ index is defined in the opposite polarity of the pattern shown in Figs. 3 and 5-12, and positive SOI corresponds to La Niña. Dashed horizontal lines indicate the $95 \%$ confidence level, based on the $t$-test. The year refers to the center of a given 21-year window. (a, b) Reprinted from Chowdary et al. (2012); (c) Reprinted from Kubota et al. (2015). 
inertia. The positive feedback of IPOC explains why El Niño stages its last act over the Indo-Northwest Pacific region in JJA(1), why the North IO-SCS warming peaks twice, and why the AAC is the dominant mode of summer atmospheric variability over the Northwest Pacific. These results, along with the recognition that the IOD is a coupled mode of Bjerknes feedback excited by ENSO (Saji et al., 1999), transform our view of the IO from a slave to ENSO to a dynamic player shaping regional climate variability (Annamalai et al., 2005; Kug and Kang, 2006; Luo et al., 2012; Han et al., 2014; Li et al., 2015c).

Models show skill in predicting the IPOC mode at monthly to seasonal leads, especially after a major El Niño event (Wang et al., 2009; Chowdary et al., 2010). Although the PJ pattern transmits tropical signals poleward, seasonal predictability is limited over extratropical East Asia due to the interference by stationary wave trains trapped along the Asian westerly jet (Kosaka et al., 2012). Models simulate these stationary wave patterns well, but not their temporal phase. Further work is needed to quantify seasonal predictability over East Asia, including the contribution from the PJ pattern and limitations imposed by the Silk Road pattern. Extra predictability might be achieved by improving the simulation of the Mei-yu rain band in light of the im-

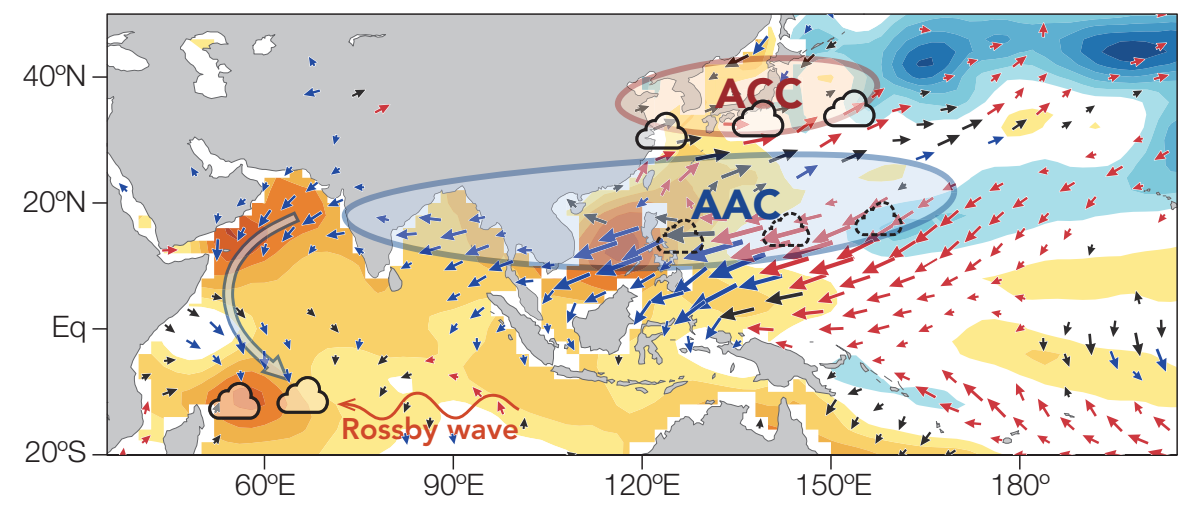

Fig. 15. Schematic representation of cross-basin Indo-Pacific ocean-atmosphere interaction in JJA(1) following El Niño: anomalies of SST (color shading), surface wind (vectors), and SLP (shaded ellipses). The easterly wind anomalies associated with the AAC cause SST to increase over the North IO-SCS (blue vectors) and to decrease in the easterly regime of the Northwest Pacific (red vectors), while the SST anomalies anchor the AAC by suppressing atmospheric convection over the TNW Pacific. The slow propagating oceanic Rossby waves in the South IO (red wavy arrow) also contribute to the easterly wind anomalies over the North IO (box arrow). Convection is suppressed in the AAC but enhanced over East Asia in the anomalous cyclonic circulation (ACC) of the PJ pattern.
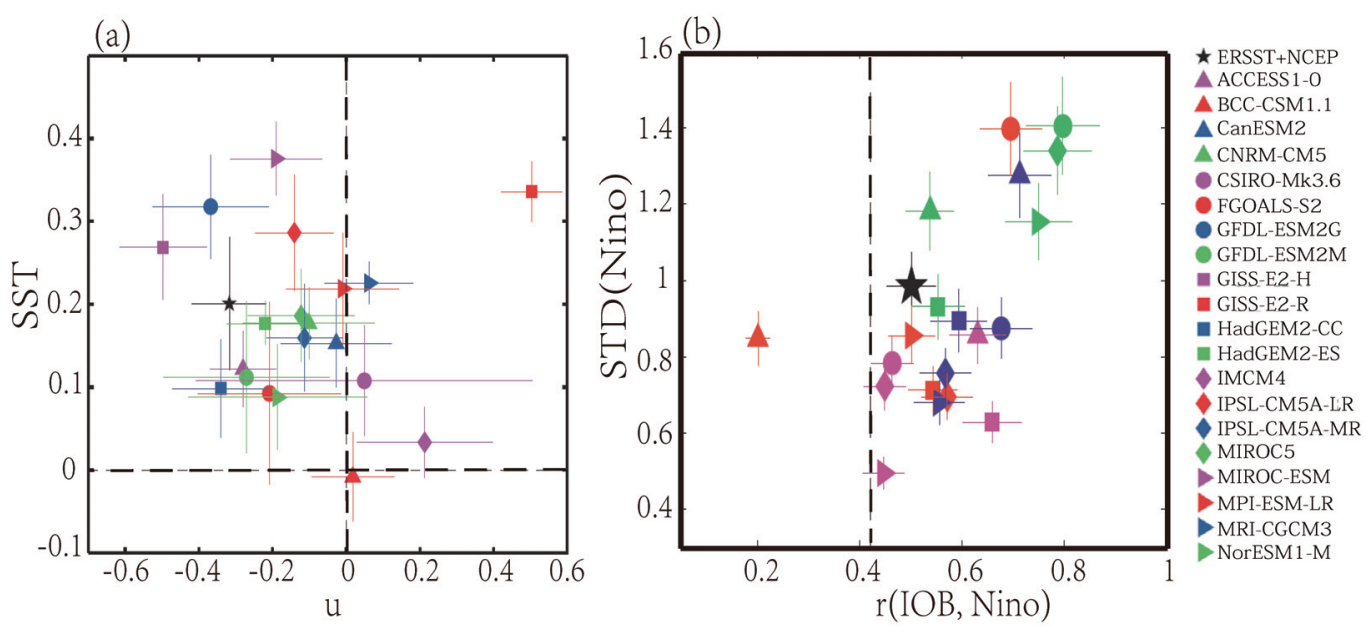

Fig. 16. Scatter diagrams (a) between zonal wind $\left(\mathrm{m} \mathrm{s}^{-1}\right)$ and SST $\left({ }^{\circ} \mathrm{C}\right)$ anomalies in the North $\mathrm{IO}\left(0^{\circ}-15^{\circ} \mathrm{N}\right.$, $\left.50^{\circ}-100^{\circ} \mathrm{E}\right)$ in $\operatorname{AMJ}(1)$ and $(b)$ between the standard deviation of $\mathrm{NDJ}(0 / 1) \mathrm{Niño} 3.4$ index [STD(Niño)] and the correlation of the JJA(1) tropical IO basin-mean SST [r(IOB, Niño)], based on historical runs with 20 CMIP5 models (error bars give ranges of one standard deviation). Reprinted from Du et al. (2013). 
portance of midlatitude latent heating for the PJ pattern (Lu and Lin, 2009). Prediction systems with a high-resolution (50 $\mathrm{km}$ or finer grid spacing) atmospheric model component hold the promise of predicting TC track density and even landfall probability at seasonal leads (Vecchi et al., 2014; Mei et al., 2015).

Historical correlations of summer anomalies over the Indo-TNW Pacific with the preceding winter ENSO were not stable over time- - high at the turn of the 20th century and after the 1970s, but low in between. The ENSO variance cycle seems to be a driver: strong ENSO excites a robust IPOC mode with enhanced PJ variance (Chowdary et al., 2012; Kubota et al., 2015). Bursts of strong ENSO events tend to cluster in time to form a variance cycle (Li et al., 2013). Because it affects the seasonal predictability, work is needed to investigate the mechanism for the ENSO variance cycle and its modulations of teleconnective effects (Ogata et al., 2013; Wittenberg et al., 2014).

CGCMs are an important tool for seasonal prediction and future projection. Many CGCMs show skill in simulating the El Niño-induced IO warming (Saji et al., 2006), its seasonal evolution, and the underlying mechanisms (e.g., ocean Rossby waves in the South IO) (Du et al., 2013). Consistent with the IPOC mechanism, the SST warming and easterly wind anomalies in early summer of the El Niño decay year are correlated in the inter-model spread of CMIP5, and ENSO variance modulates the magnitude of the post-El Niño IO warming (Fig. 16). A common bias of CMIP5 models is that the El Niño-induced IO warming and AAC terminate 1-2 months too early and do not persist through summer as in observations (Du et al., 2013; Hu et al., 2014). This bias of weak summer persistence might be due to a weak thermocline feedback of slow-propagating Rossby waves over the southwest IO - a mechanism that contributes to the persistence of the IPOC mode (Du et al., 2009). The thermocline ridge is too deep due to a downwelling Ekman pumping bias related to too weak westerly winds in the equatorial IO ( $\mathrm{Li}$ et al., 2015a). The equatorial wind biases can be further traced back to biases in simulating the southwest summer monsoon (Li et al., 2015b), illustrating the importance of IO-monsoon interaction.

The tropical IO has experienced a robust warming since the 1950s - a change due to anthropogenic radiative forcing (Alory et al., 2007; Du and Xie, 2008). While there are some uncertainties in the magnitude and spatial pattern of the IO warming trend in observations (Tokinaga et al., 2012; Han et al., 2014), CMIP5 models project a robust IOD-like warming pattern over the equatorial IO, with anomalous easterlies blowing from the reduced warming in the east to the enhanced warming in the west (Zheng et al., 2013; Christensen et al., 2013). The easterly wind change under global warming deepens the thermocline ridge in the Southwest IO, and can potentially reduce the IPOC persistence. Recent studies have questioned the reliability of the IOD-like projection on the grounds that the easterly errors in the mean wind over the equatorial IO bias Bjerknes feedback too strongly in models (Cai and Cowan, 2013; Li et al., 2016 ${ }^{\mathrm{a}}$ ). Consistent with this argument, the variance of the interannual IOD mode is too high in models (Liu et al., 2014).

The IO is projected to warm more in response to anthropogenic radiative forcing. An early study based on a single model (Zheng et al., 2011) showed that in a warmer climate both the IO warming and AAC persist longer in post-El Niño summer, indicating a strengthening of the positive feedback from the interaction of these interannual ocean-atmosphere anomalies. A similar strengthening of the IPOC mode takes place in a subset of CMIP5 models that are deemed to simulate the mode well in current climate (Chu et al., 2014). Hu et al. (2014) showed that by changing the moist adiabatic lapse rate, climate warming amplifies the tropospheric Kelvin wave that connects the Indo-western Pacific oceans in post-El Niño summer. Other competing mechanisms, e.g., the increased dry stability of the troposphere acting to reduce the circulation response to latent heating, may cause models to differ in their IPOC response to global warming. Developing a predictive understanding of regional climate change (including modes of variability) is a grand challenge facing the climate research community (Xie et al., 2015), where climate dynamics can be applied and extended.

Acknowledgements. Ya-Li YANG drew Fig. 3 and helped with the literature search for section 2.1. The work was supported by the National Basic Research Program of China (Grant No. 2012CB 955600), the U.S. National Science Foundation, the Strategic Priority Research Program of the Chinese Academy of Sciences (Grant No. XDA11010103), the Environment Research and Technology Development Fund 2-1503 of the Japanese Ministry of Environment, the Japan Society for the Promotion of Science Grant-in-Aid for Scientific Research 25287120 and for Young Scientists 15H05466, and the National Natural Science Foundation of China (Grant Nos. 41205049, 41275081, 41425019, 41525019, 41521005).

Open Access This article is distributed under the terms of the Creative Commons Attribution 4.0 International License (http://creativecommons.org/licenses/by/4.0/), which permits unrestricted use, distribution, and reproduction in any medium, provided you give appropriate credit to the original author(s) and the source, provide a link to the Creative Commons license, and indicate if changes were made.

\section{REFERENCES}

Alexander, M. A., I. Bladé, M. Newman, J. R. Lanzante, N. C. Lau, and J. D. Scott, 2002: The atmospheric bridge: The influence of ENSO teleconnections on air-sea interaction over the global oceans. J. Climate, 15, 2205-2231.

Allan, R., and T. Ansell, 2006: A new globally complete monthly historical gridded mean sea level pressure dataset (HadSLP2):

${ }^{a}$ Li, G., S.-P. Xie, and Y. Du, 2016: A robust but spurious pattern of climate change in model projections over the tropical Indian Ocean. J. Climate, submitted. 
1850-2004. J. Climate, 19, 5816-5842.

Alory, G., S. Wijffels, and G. Meyers, 2007: Observed temperature trends in the Indian Ocean over 1960-1999 and associated mechanisms. Geophys. Res. Lett., 34, L02606, doi: 10.1029/ 2006GL028044.

Annamalai, H., S.-P. Xie, J. P. McCreary, and R. Murtugudde, 2005: Impact of Indian Ocean Sea surface temperature on developing El Niño. J. Climate, 18, 302-319.

Arai, M., and M. Kimoto, 2008: Simulated interannual variation in summertime atmospheric circulation associated with the East Asian monsoon. Climate Dyn., 31, 435-447.

Cai, W. J., and T. Cowan, 2013: Why is the amplitude of the Indian Ocean dipole overly large in CMIP3 and CMIP5 climate models? Geophys. Res. Lett., 40, 1200-1205, doi: 10.1002/grl. 50208.

Cao, J., R. Y. Lu, J. M. Hu, and H. Wang, 2013: Spring Indian Ocean-western Pacific SST contrast and the East Asian summer rainfall anomaly. Adv. Atmos. Sci., 30, 1560-1568, doi: 10.1007/s00376-013-2298-6.

Chang, C. P., Y. S. Zhang, and T. Li, 2000: Interannual and interdecadal variations of the East Asian summer monsoon and tropical Pacific SSTs. Part I: Roles of the subtropical ridge. $J$. Climate, 13, 4310-4325.

Chen, W., J.-K. Park, B. W. Dong, R. Y. Lu, and W.-S. Jung, 2012: The relationship between El Niño and the western North Pacific summer climate in a coupled GCM: Role of the transition of El Niño decaying phases. J. Geophys. Res., 117, D12111, doi: 10.1029/2011JD017385.

Chen, W., J.-Y. Lee, R. Y. Lu, B. W. Dong, and K.-J. Ha, 2015: Intensified impact of tropical Atlantic SST on the western North Pacific summer climate under a weakened Atlantic thermohaline circulation. Climate Dyn., 45, 2033-2046.

Chen, Z. S., Z. P. Wen, R. G. Wu, X. B. Lin, and J. B. Wang, 2015: Relative importance of tropical SST anomalies in maintaining the Western North Pacific anomalous anticyclone during El Niño to La Niña transition years. Climate Dyn., 1-15.

Choi, K.-S., C.-C. Wu, and E.-J. Cha, 2010: Change of tropical cyclone activity by Pacific-Japan teleconnection pattern in the western North Pacific. J. Geophys. Res., 115, D19114.

Chowdary, J. S., S.-P. Xie, J.-Y. Lee, Y. Kosaka, and B. Wang, 2010: Predictability of summer Northwest Pacific climate in 11 coupled model hindcasts: Local and remote forcing. $J$. Geophys. Res., 115, D22121, doi: 10.1029/2010JD014595.

Chowdary, J. S., S.-P. Xie, J.-J. Luo, J. Hafner, S. Behera, Y. Masumoto, and T. Yamagata, 2011: Predictability of Northwest Pacific climate during summer and the role of the tropical Indian Ocean. Climate Dyn., 36, 607-621.

Chowdary, J. S., S.-P. Xie, H. Tokinaga, Y. M. Okumura, H. Kubota, N. Johnson and X.-T. Zheng, 2012: Interdecadal variations in ENSO teleconnection to the Indo-Western Pacific for 1870-2007. J. Climate, 25, 1722-1744.

Chowdary, J. S., C. Gnanaseelan, and S. Chakravorty, 2013: Impact of northwest Pacific anticyclone on the Indian summer monsoon region. Theor. Appl. Climatol., 113, 329-336.

Chowdary, J. S., and Coauthors, 2014: Seasonal prediction of distinct climate anomalies in summer 2010 over the tropical Indian Ocean and South Asia. J. Meteor. Soc. Japan, 92, 1-16.

Christensen, J. H., and Coauthors, 2013: Climate phenomena and their relevance for future regional climate change. Climate Change 2013: The Physical Science Basis. Contribution of Working Group I to the Fifth Assessment Report of the Intergovernmental Panel on Climate Change, T. F. Stocker et al.,
Eds., Cambridge University Press, 1217-1308, doi: 10.1017/ CBO9781107415324.028.

Chu, J.-E., K.-J. Ha, J.-Y. Lee, B. Wang, B.-H. Kim, and C. E. Chung, 2014: Future change of the Indian Ocean basin-wide and dipole modes in the CMIP5. Climate Dyn., 43, 535-551.

Diaz, H. F., M. P. Hoerling, and J. K. Eischeid, 2001: ENSO variability, teleconnections and climate change. Int. J. Climatol., 21, 1845-1862.

Ding, H., R. J. Greatbatch, J. Lu, and B. Cash, 2015: The East Asian summer monsoon in pacemaker experiments driven by ENSO. Ocean Dynamics, 65, 385-393.

Ding, Q. H., and B. Wang, 2005: Circumglobal teleconnection in the Northern Hemisphere summer. J. Climate, 18, 3483 3505.

Ding, Q. H., B. Wang, J. M. Wallace, and G. Branstator, 2011: Tropical-extratropical teleconnections in boreal summer: Observed interannual variability. J. Climate, 24, 1878-1896.

Ding, Y. H., and J. C. L. Chan, 2005: The East Asian summer monsoon: an overview. Meteor. Atmos. Phys., 89, 117-142.

Du, Y., and S.-P. Xie, 2008: Role of atmospheric adjustments in the tropical Indian Ocean warming during the 20th century in climate models. Geophys. Res. Lett., 35, L08712, doi: 10.1029/ 2008GL033631.

Du, Y., S.-P. Xie, G. Huang, and K. M. Hu, 2009: Role of air-sea interaction in the long persistence of El Niño-induced north Indian Ocean warming. J. Climate, 22, 2023-2038.

Du, Y., L. Yang, and S.-P. Xie, 2011: Tropical Indian Ocean influence on Northwest Pacific tropical cyclones in summer following strong El Niño. J. Climate, 24, 315-322.

Du, Y., S.-P. Xie, Y. L. Yang, X. T. Zheng, L. Liu, and G. Huang, 2013: Indian Ocean variability in the CMIP5 multimodel ensemble: The Basin mode. J. Climate, 26, 7240-7266.

Enomoto, T., 2004: Interannual variability of the Bonin high associated with the propagation of Rossby waves along the Asian jet. J. Meteor. Soc. Japan, 82, 1019-1034.

Feng, J., W. Chen, C. Y. Tam, and W. Zhou, 2011: Different impacts of El Niño and El Niño Modoki on China rainfall in the decaying phases. Int. J. Climatol., 31, 2091-2101.

Feng, J., L. Wang, and W. Chen, 2014: How does the East Asian summer monsoon behave in the decaying phase of El Niño during different PDO phases? J. Climate, 27, 2682-2698.

Gill, A. E., 1980: Some simple solutions for heat-induced tropical circulation. Quart. J. Roy. Meteor. Soc., 106, 447-462.

Han, W. Q., J. Vialard, M. J. McPhaden, T. Lee, Y. Masumoto, M. Feng, and W. P. M. de Ruijter, 2014: Indian Ocean decadal variability: A review. Bull. Amer. Meteor. Soc., 95, 1679 1703, doi: 10.1175/BAMS-D-13-00028.1.

Harrison, D. E., and N. K. Larkin, 1996: The COADS Sea level pressure signal: A near-global El Niño composite and time series view, 1946-1993. J. Climate, 9, 3025-3055.

Hirota, N., and M. Takahashi, 2012: A tripolar pattern as an internal mode of the East Asian summer monsoon. Climate Dyn., 39, 2219-2238.

Hong, C.-C., T.-C. Chang, and H.-H. Hsu, 2014: Enhanced relationship between the tropical Atlantic SST and the summertime western North Pacific subtropical high after the early 1980s. J. Geophys. Res., 119, 3715-3722.

Horel, J. D., and J. M. Wallace, 1981: Planetary-scale atmospheric phenomena associated with the Southern oscillation. Mon. Wea. Rev., 109, 813-829.

Hoskins, B. J., and D. J. Karoly, 1981: The steady linear response of a spherical atmosphere to thermal and orographic forcing. 
J. Atmos. Sci., 38, 1179-1196.

Houze, R. A., Jr., K. L. Rasmussen, S. Medina, S. R. Brodzik, and U. Romatschke, 2011: Anomalous atmospheric events leading to the Summer 2010 floods in Pakistan. Bull. Am. Meteor. Soc., 92, 291-298.

Hu, K. M., G. Huang, and R. H. Huang, 2011: The impact of tropical Indian Ocean variability on summer surface air temperature in China. J. Climate, 24, 5365-5377.

Hu, K. M., G. Huang, X. Qu, and R. H. Huang, 2012: The Impact of Indian Ocean variability on high temperature extremes across the southern Yangtze River Valley in late summer. $A d v$. Atmos. Sci., 29, 91-100, doi: 10.1007/s00376-011-0209-2.

Hu, K. M., G. Huang, X.-T. Zheng, S.-P. Xie, X. Qu, Y. Du, and L. Liu, 2014: Interdecadal variations in ENSO influences on Northwest Pacific-East Asian early summertime climate simulated in CMIP5 models. J. Climate, 27, 5982-5998.

Huang, G., K. M. Hu, and S.-P. Xie, 2010: Strengthening of tropical Indian Ocean teleconnection to the Northwest Pacific since the Mid-1970s: An atmospheric GCM study. J. Climate, 23, 5294-5304.

Huang, R. H., and F. Sun, 1992: Impact of the tropical western Pacific on the East Asian summer monsoon. J. Meteor. Soc. Japan, 70, 213-256.

Huang, R. H., and Y. F. Wu, 1989: The influence of ENSO on the summer climate change in China and its mechanism. $A d v$. Atmos. Sci., 6, 21-32, doi: 10.1007/BF02656915.

Huang, R. H., W. Chen, B. L. Yang, and R. H. Zhang, 2004: Recent advances in studies of the interaction between the East Asian winter and summer monsoons and ENSO cycle. Adv. Atmos. Sci., 21, 407-424, doi: 10.1007/BF02915568.

Hsu, H.-H., and S.-M. Lin, 2007: Asymmetry of the tripole rainfall pattern during the East Asian summer. J. Climate, 20, 44434458, doi: 10.1175/JCLI4246.1.

Izumo, T., C. B. Montégut, J.-J. Luo, S. K. Behera, S. Masson, and T. Yamagata, 2008: The role of the western Arabian Sea upwelling in Indian monsoon rainfall variability. J. Climate, 21, 5603-5623.

Jiang, X. W., S. Yang, J. P. Li, Y. Q. Li, H. R. Hu, and Y. Lian, 2013: Variability of the Indian Ocean SST and its possible impact on summer western North Pacific anticyclone in the NCEP climate forecast system. Climate Dyn., 41, 2199-2212, doi: 10.1007/s00382-013-1934-2.

Kawamura, R., T. Matsuura, S. Iizuka, 2001: Role of equatorially asymmetric sea surface temperature anomalies in the Indian Ocean in the Asian summer monsoon and El Niño-Southern oscillation coupling. J. Geophys. Res., 106(D5), 4681-4693.

Kent, E. C., S. D. Woodruff, and D. I. Berry, 2007: Metadata from WMO publication No. 47 and an assessment of Voluntary observing ship observation heights in ICOADS. J. Atmos. Oceanic Technol., 24, 214-234.

Kim, J.-S., R. C.-Y. Li, and W. Zhou, 2012: Effects of the PacificJapan teleconnection pattern on tropical cyclone activity and extreme precipitation events over the Korean peninsula. $J$. Geophys. Res., 117, D18109.

Klein, S. A., B. J. Soden, and N.-C. Lau, 1999: Remote sea surface temperature variations during ENSO: Evidence for a tropical atmospheric bridge. J. Climate, 12, 917-932.

Kobayashi, S., and Coauthors, 2015: The JRA-55 Reanalysis: General specifications and basic characteristics. J. Meteor. Soc. Japan, 93, 5-48.

Kosaka, Y., and H. Nakamura, 2006: Structure and dynamics of the summertime Pacific-Japan teleconnection pattern. Quart.
J. Roy. Meteor. Soc., 132, 2009-2030.

Kosaka, Y., and H. Nakamura, 2010: Mechanisms of meridional teleconnection observed between a summer monsoon system and a subtropical anticyclone. Part I: The Pacific-Japan pattern. J. Climate, 23, 5085-5108.

Kosaka, Y., H. Nakamura, M. Watanabe, and M. Kimoto, 2009: Analysis on the dynamics of a wave-like teleconnection pattern along the summertime Asian jet based on a reanalysis dataset and climate model simulations. J. Meteor. Soc. Japan, 87, 561-580.

Kosaka, Y., S.-P. Xie, and H. Nakamura, 2011: Dynamics of interannual variability in summer precipitation over East Asia. $J$. Climate, 24, 5435-5453.

Kosaka, Y., J. S. Chowdary, S.-P. Xie, Y.-M. Min, and J.-Y. Lee, 2012: Limitations of seasonal predictability for summer climate over East Asia and the Northwestern Pacific. J. Climate, 25, 7574-7589.

Kosaka, Y., S.-P. Xie, N.-C. Lau, and G. A. Vecchi, 2013: Origin of seasonal predictability for summer climate over the Northwestern Pacific. Proceedings of the National Academy of Sciences of the United States of America, 110, 7574-7579.

Kubota, H., Y. Kosaka, and S.-P. Xie, 2015: A 117-year long index of the Pacific-Japan pattern with application to interdecadal variability. Int. J. Climatol., doi: 10.1002/joc.4441.

Kug, J.-S., and I.-S. Kang, 2006: Interactive feedback between ENSO and the Indian Ocean. J. Climate, 19, 1784-1801, doi: 10.1175/JCLI3660.1

Kurihara, K., and T. Tsuyuki, 1987: Development of the barotropic high around Japan and its association with Rossby wavelike propagations over the North Pacific: Analysis of August 1984. J. Meteor. Soc. Japan, 65, 237-246.

Lau, N.-C., and M. J. Nath, 1996: The role of the "atmospheric bridge" in linking tropical Pacific ENSO events to extratropical SST anomalies. J. Climate, 9, 2036-2057.

Lau, N.-C., and M. J. Nath, 2003: Atmosphere-ocean variations in the Indo-Pacific sector during ENSO episodes. J. Climate, 16(1), 3-20.

Lau, W. K. M., and K.-M. Kim, 2012: The 2010 Pakistan flood and Russian heat wave: Heleconnection of hydrometeorological extremes. Journal of Hydrometeorology, 13, 392-403.

Lee, J.-Y., B. Wang, Q. Ding, K.-J. Ha, J.-B. Ahn, A. Kumar, B. Stern, and O. Alves, 2011: How predictable is the northern hemisphere summer upper-tropospheric circulation? Climate Dyn., 37, 1189-1203.

Lee, J.-Y., B. Wang, K.-H. Seo, J.-S. Kug, Y.-S. Choi, Y. Kosaka, and K.-J. Ha, 2014: Future change of Northern Hemisphere summer tropical-extratropical teleconnection in CMIP5 models. J. Climate, 27, 3643-3664.

Li, C. F., R. Y. Lu, and B. W. Dong, 2012: Predictability of the western North Pacific summer climate demonstrated by the coupled models of ENSEMBLES. Climate Dyn., 39, 329346.

Li, G., S.-P. Xie, and Y. Du, 2015a: Climate model errors over the South Indian Ocean thermocline dome and their effect on the basin mode of interannual variability. J. Climate, 28, 3093 3098.

Li, G., S.-P. Xie, and Y. Du, 2015b: Monsoon-induced biases of climate models over the tropical Indian Ocean. J. Climate, 28, 3058-3072, doi: 10.1175/JCLI-D-14-00740.1.

Li, J. B., and Coauthors, 2013: El Niño modulations over the past seven centuries. Nature Climate Change, 3, 822-826.

Li, S. L., J. Lu, G. Huang, and K. M. Hu, 2008: Tropical Indian 
Ocean basin warming and East Asian summer monsoon: a multiple AGCM study. J. Climate, 21, 6080-6088.

Li, T. M., and B. Wang, 2005: A review on the western North Pacific monsoon: Synoptic-to-interannual variabilities. Terrestrial, Atmospheric and Oceanic Sciences, 16, 285-314.

Li, X. C., S.-P. Xie, S. T. Gille, and C. Yoo, 2015c: Atlanticinduced pan-tropical climate change over the past three decades. Nature Clim. Change, doi: 10.1038/NCLIMATE 2840.

Li, X. Z., W. Zhou, D. L. Chen, C. Y. Li, and J. Song, 2014: Water vapor transport and moisture budget over Eastern China: Remote forcing from the two types of El Niño. J. Climate, 27, 8778-8792.

Liang, J. Y., S. Yang, Z. Z. Hu, B. H. Huang, A. Kumar, and Z. Q. Zhang, 2009: Predictable patterns of the Asian and IndoPacific summer precipitation in the NCEP CFS. Climate Dyn., 32, 989-1001.

Liu, L., S.-P. Xie, X.-T. Zheng, T. Li, Y. Du, G. Huang, and W.-D. Yu, 2014: Indian Ocean variability in the CMIP5 multi-model ensemble: The zonal dipole mode. Climate Dyn., 43, 17151730, doi: 10.1007/s00382-013-2000-9.

Liu, Z. Y., and M. Alexander, 2007: Atmospheric bridge, oceanic tunnel, and global climatic teleconnections. Rev. Geophys., 45, RG2005, doi: 10.1029/2005RG000172.

Lu, R. Y., and Z. D. Lin, 2009: Role of subtropical precipitation anomalies in maintaining the summertime meridional teleconnection over the western North Pacific and East Asia. $J$. Climate, 22, 2058-2072.

Lu, R. Y., and S. Lu, 2014: Local and remote factors affecting the SST-precipitation relationship over the western North Pacific during summer. J. Climate, 27, 5132-5147.

Lu, R. Y., Y. Li, and B. W. Dong, 2006: External and internal summer atmospheric variability in the western North Pacific and East Asia. J. Meteor. Soc. Japan, 84, 447-462.

Lu, R.-Y., C.-F. Li, S.-H. Yang, and B. W. Dong, 2012: The coupled model predictability of the western North Pacific summer monsoon with different leading times. Atmospheric and Oceanic Science Letters, 5, 219-224.

Luo, J.-J., S. Masson, S. Behera, and T. Yamagata, 2008: Extended ENSO predictions using a fully coupled ocean-atmosphere model. J. Climate, 21, 84-93.

Luo, J.-J., W. Sasaki, and Y. Masumoto, 2012: Indian Ocean warming modulates Pacific climate change. Proceedings of the $\mathrm{Na}$ tional Academy of Sciences of the United States of America, 109, 18 701-18 706.

Masumoto, Y., and G. Meyers, 1998: Forced Rossby waves in the southern tropical Indian Ocean. J. Geophys. Res., 103(C12), 27 589-27 602.

Matsuno, T., 1966: Quasi-geostrophic motions in the equatorial area. J. Meteor. Soc. Japan, 44, 25-43.

Mei, W., S.-P. Xie, M. Zhao, and Y. Q. Wang, 2015: Forced and internal variability of tropical cyclone track density in the western North Pacific. J. Climate, 28, 143-167.

Mishra, V., B. V. Smoliak, D. P. Lettenmaier, and J. M. Wallace, 2012: A prominent pattern of year-to-year variability in Indian summer monsoon rainfall. Proceedings of the National Academy of Sciences of the United States of America, 109, 7213-7217, doi: 10.1073/pnas.1119150109.

Neelin, J. D., and H. Su, 2005: Moist teleconnection mechanisms for the tropical South American and Atlantic sector. J. Climate, 18, 3928-3950.

Nigam, S., and H.-S. Shen, 1993: Structure of Oceanic and Atmo- spheric Low-Frequency Variability over the Tropical Pacific and Indian Oceans. Part I: COADS observations. J. Climate, 6, 657-676.

Nitta, T., 1986: Long-term variations of cloud amount in the western Pacific region. J. Meteor. Soc. Japan, 64, 373-390.

Nitta, T., 1987: Convective activities in the tropical western Pacific and their impact on the Northern Hemisphere summer circulation. J. Meteor. Soc. Japan, 65, 373-390.

Ogata, T., S.-P. Xie, A. Wittenberg, and D.-Z. Sun, 2013: Interdecadal amplitude modulation of El Niño-Southern oscillation and its impact on tropical Pacific decadal variability. $J$. Climate, 26, 7280-7297.

Ohba, M., and H. Ueda, 2006: A role of zonal gradient of SST between the Indian Ocean and the western Pacific in localized convection around the Philippines. Scientific Online Lettrs on the Atmosphere, 2, 176-179, doi: 10.2151/sola.2006-045.

Otomi, Y., Y. Tachibana, and T. Nakamura, 2013: A possible cause of the AO polarity reversal from winter to summer in 2010 and its relation to hemispheric extreme summer weather. $\mathrm{Cli}$ mate Dyn., 40, 1939-1947.

Pai, D. S., and O. P. Sreejith, 2011: Global and Regional circulation anomalies: A report. A. Tyagi et al., Eds., IMD Met. Monograph No. Synoptic Meteorology No.10/2011, IMD, 63-78.

Park, H.-S., J. C. H. Chiang, B. R. Lintner, and G. J. Zhang, 2010: The delayed effect of major El Niño events on Indian monsoon rainfall. J. Climate, 23, 932-946.

Perigaud, C., and P. Delecluse, 1993: Interannual Sea level variations in the tropical Indian Ocean from geosat and shallow water simulations. J. Phys. Oceanogr., 23, 1916-1934.

Rong, X. Y., R. H. Zhang, and T. Li, 2010: Impacts of Atlantic sea surface temperature anomalies on Indo-East Asian summer monsoon-ENSO relationship. Chinese Science Bulletin, 55, 2458-2468.

Saha, K., 1970: Zonal anomaly of sea surface temperature in equatorial Indian Ocean and its possible effect upon monsoon circulation. Tellus, 22, doi: 10.1111/j.2153-3490.1970.tb00506, 403-409. $x$.

Saji, N. H., B. N. Goswami, P. N. Vinayachandran, and T. Yamagata, 1999: A dipole mode in the tropical Indian Ocean. Nature, 401, 360-363.

Saji, N. H., S.-P. Xie, and T. Yamagata, 2006: Tropical Indian Ocean variability in the IPCC twentieth-century climate simulations. J. Climate, 19, 4397-4417.

Schott, F. A., S.-P. Xie, and J. P. McCreary Jr, 2009: Indian Ocean circulation and climate variability. Rev. Geophys, 47, RG1002, doi: 10.1029/2007RG000245.

Shen, S. H., and K.-M. Lau, 1995: Biennial oscillation associated with the East Asian summer monsoon and tropical sea surface temperatures. J. Meteor. Soc. Japan, 73, 105-124.

Simmons, A. J., J. M. Wallace, and G. W. Branstator, 1983: Barotropic wave propagation and instability, and atmospheric teleconnection patterns. J. Atmos. Sci., 40, 1363-1392.

Smith, T. M., R. W. Reynolds, T. C. Peterson, and J. Lawrimore, 2008: Improvements to NOAA's Historical Merged LandOcean Surface Temperature Analysis (1880-2006). J. Climate, 21, 2283-2296.

Stuecker, M. F., A. Timmermann, F.-F. Jin, S. McGregor, and H.L. Ren, 2013: A combination mode of the annual cycle and the El Niño/Southern oscillation. Nature Geoscience, 6, 540 544.

Stuecker, M. F., F.-F. Jin, A. Timmermann, and S. McGregor, 
2015: Combination mode dynamics of the anomalous Northwest Pacific anticyclone. J. Climate, 28, 1093-1111.

Sun, X. G., R. J. Greatbatch, W. Park, and M. Latif, 2010: Two major modes of variability of the East Asian summer monsoon. Quart. J. Roy. Meteor. Soc., 136, 829-841.

Terao, T., and T. Kubota, 2005: East-west SST contrast over the tropical oceans and the post El Niño western North Pacific summer monsoon. Geophys. Res. Lett., 32, L15706.

Tokinaga, H., S.-P. Xie, A. Timmermann, S. McGregor, T. Ogata, H. Kubota, and Y. M. Okumura, 2012: Regional patterns of tropical Indo-Pacific climate change: Evidence of the Walker Circulation weakening. J. Climate, 25, 1689-1710.

Trenberth, K. E., G. W. Branstator, D. Karoly, A. Kumar, N.-C. Lau, and C. Ropelewski, 1998: Progress during TOGA in understanding and modeling global teleconnections associated with tropical sea surface temperatures. J. Geophys. Res., 103, 14 291-14 324.

Tsuyuki, T., and K. Kurihara, 1989: Impact of convective activity in the west-ern tropical Pacific on the East Asian summer circulation. J. Meteor. Soc. Japan, 67, 231-247.

Ueda, H., and J. Matsumoto, 2000: A possible triggering process of east-west asymmetric anomalies over the Indian Ocean in relation to 1997/98 El Niño. J. Meteor. Soc. Japan, 78, 803818.

Vecchi, G. A., and Coauthors, 2014: On the seasonal forecasting of regional tropical cyclone activity. J. Climate, 27, 7994-8016.

Wakabayashi, S., and R. Kawamura, 2004: Extraction of major teleconnection patterns possibly associated with the anomalous summer climate in Japan. J. Meteor. Soc. Japan, 82, $1577-1588$.

Wang, B., R. G. Wu, and X. H. Fu, 2000: Pacific-East Asian teleconnection: How does ENSO affect East Asian climate? J. Climate, 13, 1517-1536.

Wang, B., R. G. Wu, and T. Li, 2003: Atmosphere-warm ocean interaction and its impacts on Asian-Australian monsoon variation. J. Climate, 16, 1195-1211.

Wang, B., Q. H. Ding, X. H. Fu, I.-S. Kang, K. Jin, J. Shukla, and F. Doblas-Reyes, 2005: Fundamental challenge in simulation and prediction of summer monsoon rainfall. Geophys. Res. Lett., 32, L15711.

Wang, B., J. Yang, T. J. Zhou, and B. Wang, 2008: Interdecadal changes in the major modes of Asian-Australian monsoon Variability: Strengthening relationship with ENSO since the Late 1970s. J. Climate, 21, 1771-1789.

Wang, B., and Coauthors, 2009: Advance and prospectus of seasonal prediction: Assessment of the APCC/CliPAS 14-model ensemble retrospective seasonal prediction (1980-2004). Climate Dyn., 33, 93-117.

Wang, B., B. Q. Xiang, and J.-Y. Lee, 2013: Subtropical high predictability establishes a promising way for monsoon and tropical storm predictions. Proceedings of the National Academy of Sciences of the United States of America, 110, 2718-2722.

Wang, C. Z., R. H. Weisberg, and J. I. Virmani, 1999: Western Pacific interannual variability associated with the El NiñoSouthern oscillation. J. Geophys. Res., 104, 5131-5149.

Wang, C. Z., W. Q. Wang, D. X. Wang, and Q. Wang, 2006: Interannual variability of the South China Sea associated with El Niño. J. Geophys. Res., 111, C03023, doi: 10.1029/2005JC 003333.

Wang, D. X., Q. Xie, Y. Du, W. Q. Wang, and J. Chen, 2002: The 1997-1998 warm event in the South China Sea. Chinese Science Bulletin, 47, 1221-1227.
Weare, B. C., 1979: A statistical study of the relationships between ocean surface temperatures and the Indian monsoon. J. Atmos. Sci., 36, 2279-2291.

Webster, P. J., V. E. Toma, and H.-M. Kim, 2011: Were the 2010 Pakistan floods predictable? Geophys. Res. Lett., 38, L04806, doi: 10.1029/2010GL046346.

Wittenberg, A. T., A. Rosati, T. L. Delworth, G. A. Vecchi, and F. R. Zeng, 2014: ENSO modulation: Is it decadally predictable? J. Climate, 27, 2667-2681.

Wu, B., T. J. Zhou, and T. Li, 2009a: Contrast of rainfall-SST relationships in the western North Pacific between the ENSOdeveloping and ENSO-decaying summers. J. Climate, 22 , 4398-4405.

Wu, B., T. Li, and T. J. Zhou, 2010: Relative contributions of the Indian Ocean and local SST anomalies to the maintenance of the western North Pacific anomalous anticyclone during the El Niño decaying summer. J. Climate, 23, 2974-2986.

Wu, G. X., and H. Z. Liu, 1995: Neighborhood response of rainfall to tropical Sea surface temperature anomalies. Part I: numerical experiment. Chinese J. Atmos. Sci., 19, 422-434. (in Chinese)

Wu, R. G., 2002: A mid-latitude Asian circulation anomaly pattern in boreal summer and its connection with the Indian and East Asian summer monsoons. Int. J. Climatol., 22, 1879-1895.

Wu, R. G., and B. Wang, 2002: A contrast of the East Asian summer monsoon-ENSO relationship between 1962-77 and 1978-93. J. Climate, 15, 3266-3279.

Wu, R. G., Z. Z. Hu, and B. P. Kirtman, 2003: Evolution of ENSOrelated rainfall anomalies in East Asia. J. Climate, 16, 37423758.

Wu, R. G., and B. P. Kirtman, 2007: Regimes of seasonal air-sea interaction and implications for performance of forced simulations. Climate Dyn., 29, 393-410.

Wu, R. G., B. P. Kirtman, V. Krishnamurthy, 2008: An asymmetric mode of tropical Indian Ocean rainfall variability in boreal spring. J. Geophys. Res., 113(D5), D05104, doi: 10.1029/2007JD 009316.

Wu, R. G., G. Huang, Z. C. Du, and K. M. Hu, 2014: Cross-season relation of the South China Sea precipitation variability between winter and summer. Climate Dyn., 43, 193-207.

Wu, Z. W., B. Wang, J. P. Li, and F.-F. Jin, 2009b: An empirical seasonal prediction model of the East Asian summer monsoon using ENSO and NAO. J. Geophys. Res., 114, doi: 10.1029/2009JD011733.

Xiang, B. Q., B. Wang, W. D. Yu, and S. B. Xu, 2013: How can anomalous western North Pacific subtropical high intensify in late summer? Geophys. Res. Lett., 40, 2349-2354.

Xie, P. P., and P. A. Arkin, 1997: Global precipitation: A 17-year monthly analysis based on gauge observations, satellite estimates, and numerical model outputs. Bull. Amer. Meteor. Soc., 78, 2539-2558.

Xie, S.-P., and S. G. H. Philander, 1994: A coupled oceanatmosphere model of relevance to the ITCZ in the eastern Pacific. Tellus, 46, doi: 10.1034/j.1600-0870.1994.t01-100001.x.

Xie, S.-P., H. Annamalai, F. A. Schott, and J. P. McCreary Jr., 2002: Structure and mechanisms of South Indian Ocean climate variability. J. Climate, 15, 864-878.

Xie, S.-P., Q. Xie, D. X. Wang, and W. T. Liu, 2003: Summer upwelling in the South China Sea and its role in regional climate variations. J. Geophys. Res., 108, 3261, doi: 10.1029/2003JC001867. 
Xie, S.-P., K. M. Hu, J. Hafner, H. Tokinaga, Y. Du, G. Huang, and T. Sampe, 2009: Indian Ocean capacitor effect on Indowestern Pacific climate during the summer following El Niño. J. Climate, 22, 730-747.

Xie, S.-P., Y. Du, G. Huang, X.-T. Zheng, H. Tokinaga, K. M. Hu, and Q. Y. Liu, 2010: Decadal shift in El Niño influences on Indo-Western Pacific and East Asian climate in the 1970s. J. Climate, 23, 3352-3368.

Xie, S.-P., and Coauthors, 2015: Towards predictive understanding of regional climate change. Nature Clim. Change, 5, 921-930.

Yamaura, T., and T. Tomita, 2011: Spatiotemporal differences in the interannual variability of Baiu frontal activity in June. Int. J. Climatol., 31, 57-71.

Yang, J. L., Q. Y. Liu, S.-P. Xie, Z. Y. Liu, and L. X. Wu, 2007: Impact of the Indian Ocean SST basin mode on the Asian summer monsoon. Geophys. Res. Lett., 34, L02708, doi: 10.10029/2006GL028571.

Yang, Y. L., S.-P. Xie, Y. Du, and H. Tokinaga, 2015: Interdecadal difference of interannual variability characteristics of South China Sea SSTs associated with ENSO. J. Climate, 28, 71457160

Yasunaka, S., and K. Hanawa, 2006: Interannual summer temperature variations over Japan and their relation to large-scale atmospheric circulation field. J. Meteor. Soc. Japan, 84, 641652.

Ye, H., and R. Y. Lu, 2011: Subseasonal variation in ENSO-related East Asian rainfall anomalies during summer and its role in weakening the relationship between the ENSO and summer rainfall in eastern China since the late 1970s. J. Climate, 24, 2271-2284.

Yu, J. H., T. Li, Z. M. Tan, and Z. W. Zhu, 2015: Effects of tropical North Atlantic SST on tropical cyclone genesis in the western North Pacific. Climate Dyn., doi: 10.1007/s00382-015-2618$\mathrm{x}$.

Yuan, Y., and S. Yang, 2012: Impacts of different types of El Niño on the East Asian climate: Focus on ENSO cycles. J Climate, 25, 7702-7722.

Yun, K.-S., S.-W. Yeh, and K.-J. Ha, 2013: Distinct impact of tropical SSTs on summer North Pacific high and western North Pacific subtropical high. J. Geophys. Res. Atmos., 118, $4107-$ 4116.

Zhan, R. F., Y. Q. Wang, and C.-C. Wu, 2011: Impact of SSTA in the East Indian Ocean on the frequency of Northwest Pacific tropical cyclones: A regional atmospheric model study. J. Climate, 24, 6227-6242.

Zhang, R. H., A. Sumi, and M. Kimoto, 1996: Impact of El Niño on the East Asian monsoon: A diagnostic study of the ' $86 / 87$ and '91/92 events. J. Meteor. Soc. Japan, 74, 49-62.

Zheng, X. T., S.-P. Xie, and Q. Y. Liu, 2011: Response of the Indian Ocean Basin mode and its capacitor effect to global warming. J. Climate, 24, 6146-6164.

Zheng, X.-T., S.-P. Xie, Y. Du, L. Liu, G. Huang, and Q. Y. Liu, 2013: Indian Ocean Dipole response to global warming in the CMIP5 multimodel ensemble. J. Climate, 26, 6067-6080. 